\author{
UNIVERSIDADE DE SÃO PAULO \\ ESCOLA DE ENGENHARIA DE SÃO CARLOS
}

PEDRO FELIPE GARCIA MARTINS DA COSTA

Modificação química do EVA com óleo de babaçu para o desenvolvimento de blendas poliméricas de PP

São Carlos 

PEDRO FELIPE GARCIA MARTINS DA COSTA

\section{Modificação química do EVA com óleo de babaçu para o desenvolvimento de blendas poliméricas de PP}

Versão corrigida

Original na unidade

Dissertação apresentada ao Programa de Pós-graduação em Ciência e Engenharia de Materiais da Universidade de São Paulo, para obtenção de título de Mestre em Ciências.

Área de concentração: Desenvolvimento, Caracterização e Aplicação de Materiais

Orientador: Prof. Dr. Marcelo Aparecido Chinelatto

São Carlos 
Autorizo a reprodução e divulgação total ou parcial deste trabalho, por qualquer meio convencional ou eletrônico, para fins de estudo e pesquisa, desde que citada a fonte.

Ficha catalográfica elaborada pela Biblioteca Prof. Dr. Sérgio Rodrigues Fontes da EESC/USP com os dados inseridos pelo(a) autor(a).

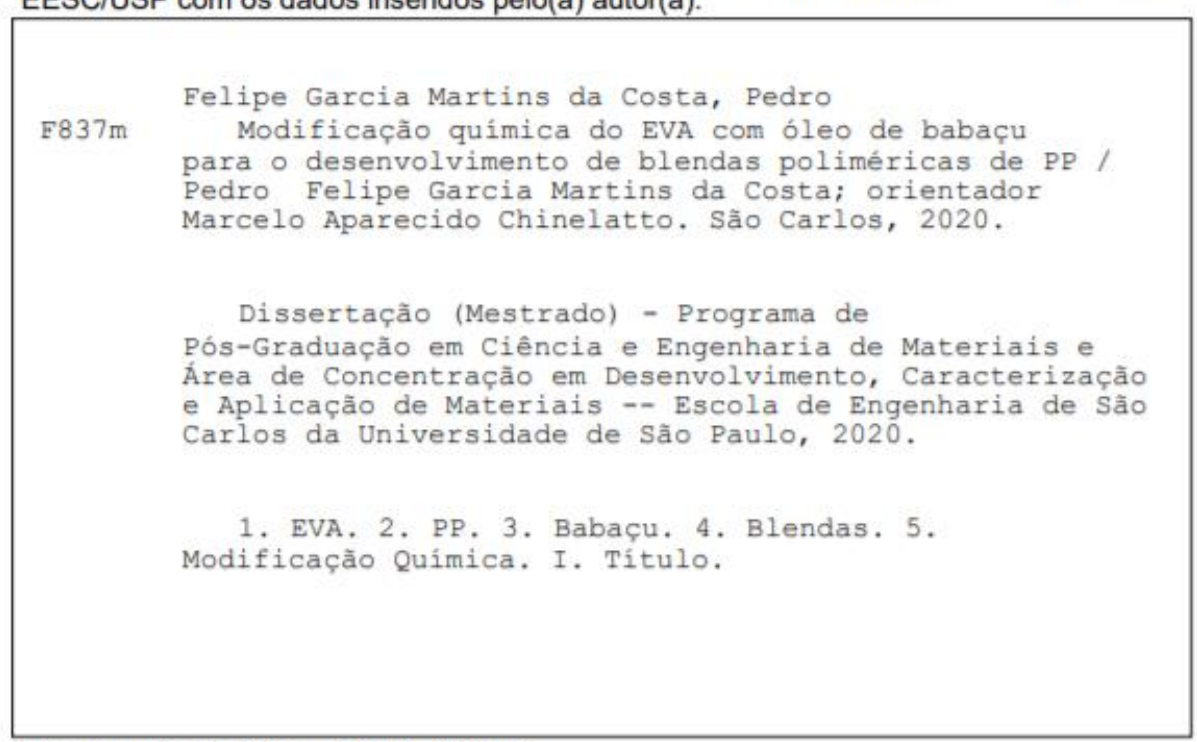

Eduardo Graziosi Silva - CRB - 8/8907 


\section{FOLHA DE JULGAMENTO}

Candidato: Bacharel PEDRO FELIPE GARCIA MARTINS DA COSTA.

Título da dissertação:"Modificação química do EVA com óleo de babaçu para o desenvolvimento de blendas poliméricas de PP".

Data da defesa: 23/10/2020.

Comissão Julgadora

Resultado

Prof. Dr. Marcelo Aparecido Chinelatto

Aprovado

(Orientador)

(Escola de Engenharia de São Carlos/EESC)

Prof. Associado Benedito dos Santos Lima Neto

Aprovado

(Instituto de Química de São Carlos/IQSC-USP)

Dr. José Manoel Marconcini

Aprovado

(Empresa Brasileira de Pesquisa Agropecuária/EMBRAPA)

Coordenador do Programa de Pós-Graduação em Engenharia de Materiais:

Prof. Associado Marcelo Falcão de Oliveira

Presidente da Comissão de Pós-Graduação:

Prof. Titular Murilo Araujo Romero 

Dedico este trabalho à minha avó, que considero como mãe, e que por algum motivo que não seí explicar, sempre está presente em meus sonhos. 



\section{AGRADECIMENTOS}

Gostaria de agradecer primeiramente aos meus pais, pelo esforço para que não faltasse nada para que eu pudesse chegar até aqui e por me dar a liberdade e apoio para seguir com as minhas escolhas.

Ao meu orientador, professor Marcelo Aparecido Chinelatto, por me dar a oportunidade e liberdade de desenvolver um projeto com conteúdo, em parte, desenvolvido por mim e que foi uma nova proposta e um desafio para o que até então era realizado pelo seu grupo de pesquisa. Agradeço pela orientação que foi além dos ensinamentos do âmbito acadêmico e contribuíram para o meu desenvolvimento pessoal. Sou grato pela paciência e preocupação comigo.

Ao professor Benedito dos Santos Lima Neto, que me apresentou a pesquisa científica e me ofereceu oportunidades durante a graduação. Também agradeço pela colaboração com ideias para a elaboração inicial do meu projeto e por oferecer o laboratório de Química Inorgânica e Analítica para o desenvolvimento da maioria da parte prática do trabalho.

Ao professor Antônio José Felix de Carvalho por oferecer as instalações do seu laboratório para a realização de experimentos.

Ao Henrique, que sempre me auxiliou com experimentos, revisões, softwares e ideias nos últimos sete anos. E por nunca negar ajuda mesmo nos momentos de prazo curto, desde que não atrapalhassem seu dia de pescaria.

Aos técnicos de laboratório, Ricardo e Jennifer, por sempre estarem dispostos a ajudar e por ensinar os procedimentos dos laboratórios.

A todos que, de alguma maneira, me ajudaram e tornaram esta fase mais leve. Aos meus colegas de laboratório do departamento de Materiais e do IQSC, da Rep., do Apezinho, da saudosa Roseta, aos quarentenados: Jéssica, Claudio e Cássia, e por aí vai.

Ao Conselho Nacional de Desenvolvimento Científico e Tecnológico (CNPq) pela bolsa de mestrado concedida e à Fundação de Amparo à Pesquisa do Estado São Paulo (FAPESP) pelo apoio oferecido ( $\mathrm{N}^{\mathrm{o}}$ de processo 2018/23542-7). 



\section{RESUMO}

COSTA, P. F. G. M. Modificação química do EVA com óleo de babaçu para o desenvolvimento de blendas poliméricas de PP. 2020. 82 p. Dissertação (Mestrado) Escola de Engenharia de São Carlos, Universidade de São Paulo, São Carlos, 2020.

O polipropileno isotático (iPP) é utilizado em diversas aplicações devido ao seu baixo custo e às suas elevadas propriedades mecânicas e térmicas em comparação a outras poliolefinas. Porém, o iPP apresenta fragilidade, principalmente a baixas temperaturas. Portanto, existe grande interesse científico em otimizar suas propriedades, como a tenacidade e a resistência à tração. Um dos métodos mais utilizados para modificar as propriedades de polímeros é por meio da elaboração de blendas poliméricas. O objetivo deste trabalho foi modificar quimicamente o copolímero poli(etileno-co-acetato de vinila), EVA, alterando sua estrutura química com a inserção de cadeias carbônicas saturadas provenientes do óleo de babaçu, visando o aumento da tenacidade e da resistência à tração em blendas iPP/EVA, em comparação ao iPP puro. Inicialmente, foi realizada a transesterificação do óleo de babaçu, seguida da hidrólise dos produtos ésteres metílicos para se obter os ácidos graxos de babaçu (AGB). Estas reações químicas e o óleo de babaçu foram caracterizados por meio de Ressonância Magnética Nuclear de Hidrogênio. O EVA utilizado neste trabalho (EVA65) contém $65 \%(\mathrm{~m} / \mathrm{m})$ de acetato de vinila. A primeira etapa da modificação química do EVA65 consistiu na sua hidrólise, na qual foi alcançado o rendimento de 83,7 \%, verificado pela retro-titulação do EVA65 hidrolisado $(\mathrm{EVAOH})$. A segunda etapa foi a esterificação do EVAOH com os AGB sintetizados. Os AGB tiveram o grupo acila ativado por meio da reação com cloreto de tionila para a formação de um cloreto de acila, o que tornou possível a reação de esterificação e a obtenção do EVA modificado (EVAm). Estas reações e os polímeros sintetizados foram caracterizados por Espectroscopia no Infravermelho por Transformada de Fourier e Termogravimetria. Ambas as técnicas confirmaram o desaparecimento dos sinais do grupo acetato de vinila do EVA65 e o aparecimento dos sinais referentes aos grupos hidroxila no EVAOH, assim como na recuperação do perfil éster do EVAm, comparado ao EVA65. O EVAm se apresentou insolúvel em todos os solventes testados. Uma hipótese para a insolubilidade do EVAm é a formação de ligações cruzadas entre as cadeias poliméricas por meio das insaturações, visto que o óleo de babaçu apresentou $13 \%$ de ácidos graxos insaturados. Foram feitas blendas de iPP/EVA65, iPP/EVAOH e iPP/EVAm por meio de pulverização em moinho criogênico seguido de dissolução, nas composições de 5 e $10 \%$ de EVAs. Ensaios de tração foram realizados e foi observado aumento na resistência à tração e no módulo de elasticidade para as blendas iPP/EVAOH. Valores menores no elongamento foram identificados em todas as blendas em comparação ao iPP puro.

Palavras-chave: EVA; PP; Babaçu; Blendas; Modificação Química. 



\begin{abstract}
COSTA, P. F. G. M. Chemical modification of EVA with babassu oil for the development of polymeric PP blends. 2020. 82 p. Thesis (Master's Degree) - Engineering School of São Carlos, University of São Paulo, São Carlos, 2020.

The isotactic polypropylene (iPP) is utilized in a wide variety of applications due to its low cost and good mechanical and thermal properties when compared to polyolefins. However, iPP presents fragility, especially at low temperatures. Therefore, there is an increasing scientific interest in optimizing its properties, such as tenacity and mechanical resistance. One of the most important methods to modify the properties of polymers is by polymeric blends. This work aims to chemically modify the copolymer poly(ethylene-co-vinyl acetate), EVA, by modifying its chemical structure with the addition of saturated organic chains from babassu oil with the aim to increase its tenacity and tensile strength in iPP/EVA blends. First, transesterification of babaçu oil, followed by hydrolysis of methyl esters to obtain babassu fatty acids (ácidos graxos de babaçu - AGB). These chemical reactions and babassu oil were characterized by Hydrogen Nuclear Magnetic Resonance. The EVA used in this work (EVA65) contains $65 \%(\mathrm{~m} / \mathrm{m})$ of vinyl acetate. The first step of the chemical modification of EVA65 consisted in its hydrolysis, which yielded by $83.7 \%$, verified by the retro-titulation of hydrolysed EVA65 (EVAOH). The second step was the esterification of EVAOH with synthetic AGB. The AGB had its acyl group activated by reacting with thionyl chloride to form the acyl chloride, which allowed the esterification and obtain the modified EVA (EVAm). These reactions and the synthetic polymers were characterized by Infrared Spectroscopy with Fourier transformation and Thermogravimetry. Both techniques confirmed the vanishing of vinyl acetate from EVA65 and the appearance of signals related to the hydroxyl groups from EVAOH as well as the recuperation of the ester profile from EVAm when compared to EVA65. EVAm presented insoluble in all solvents tested. An hypothesis to the insolubility of EVAm its to the presence of crosslinks between polymeric chains due to unsaturation, in the view that babassu oil presented $13 \%$ of unsaturated fat acids. Blends of iPP/EVA65, iPP/EVAOH and iPP/EVAm were made by pulverization in a cryogenic mill followed by dissolution, with compositions of 5 and $10 \%$ of EVAs. Tensile strength tests were performed from which an increase in tensile strength and Young's modulus were observed for the iPP/EVAOH blends. Lower values in the elongation were identified in all blends in comparison to pure iPP.
\end{abstract}

Keywords: EVA; PP; Babassu; Blends; Chemical Modification 



\section{LISTA DE FIGURAS}

Figura 1 - Estruturas químicas hipotéticas dos copolímeros EVA65, com grupos acetato de vinila em azul; EVAOH, com grupos hidroxila em verde; e EVAm, com cadeias graxas em vermelho.

Figura 2 - Estruturas químicas do monômero propileno e do polímero polipropileno, respectivamente.

Figura 3 - Estruturas químicas do iPP, do sPP e do aPP, respectivamente.

Figura 4 - Estrutura química do copolímero poli(etileno-co-acetato de vinila), EVA, com o mero de etileno em vermelho e o de acetato de vinila em azul.

Figura 5 - Ilustração do impedimento estérico causado pelos grupos VA no copolímero EVA; (a) segmentos de cadeia de polietileno empacotados; (b) grupos VA, em azul, afastando as cadeias.

Figura 6 - Hidrólise parcial do EVA com solução aquosa de $\mathrm{NaOH}$ resultando em um terpolímero.

Figura 7 - Síntese do EVOH por dois processos diferentes: (a) transesterificação do EVA com metanol, e (b) hidrólise do EVOH com solução aquosa de $\mathrm{NaOH}$.

Figura 8 - Estrutura molecular de alguns ácidos graxos comuns em triglicerídeos. 38

Figura 9 - Estrutura de um triglicerídeo genérico composto por três ácidos graxos diferentes esterificados a uma molécula de glicerol, em azul. 38

Figura 10 - Fluxograma da parte experimental. 43

Figura 11 - Etapas envolvidas na transesterificação de um triglicerídeo utilizando-se metanol.

Figura 12 - Mecanismo da transesterificação de um triglicerídeo utilizando-se metanol e $\mathrm{KOH}$. 52

Figura 13 - Mecanismo da hidrólise de um éster metílico utilizando-se solução aquosa de $\mathrm{NaOH}$. 53

Figura 14 - Mecanismo da formação do cloreto de lauroila a partir de um ácido carboxílico e cloreto de tionila, onde $\mathrm{R}$ representa uma cadeia hidrocarbônica de 11 carbonos.

Figura 15 - Ilustração de cadeias de ácidos graxos típicas em triglicerídeos. Os caracteres em vermelho denotam os hidrogênios no espectro de $\mathrm{RMN}-{ }^{1} \mathrm{H}$ da Figura 16.

Figura 16 - Espectro de $\mathrm{RMN}^{-1} \mathrm{H}$ dos triglicerídeos de babaçu em $\mathrm{CDCl}_{3}$; picos atribuídos na Figura15.

Figura 17 - Espectro de $\mathrm{RMN}-{ }^{1} \mathrm{H}$ dos ésteres metílicos de babaçu em $\mathrm{CDCl}_{3}$. 
Figura 18 - Espectro de $\mathrm{RMN}-{ }^{1} \mathrm{H}$ dos ésteres metílicos de babaçu em $\mathrm{CDCl}_{3}$

Figura 19 - Mecanismo da reação de retro-titulação. Posteriormente, o anidrido em excesso é titulado.

Figura 20 - Reação de esterificação do EVA hidrolisado com cloreto de ácido. 60

Figura 21 - Espectros FTIR do EVA65, EVAOH, AGB e EVAm. 61

Figura 22 - Curvas (a) TGA e (b) DTG dos copolímeros EVA65, EVAOH e EVAm. 63

Figura 23 - Imagens obtidas do EVA65, EVAOH e EVAm. 65

Figura 24 - a) Curvas DSC do segundo aquecimento dos copolímeros EVA65, EVAOH e EVAm; b) aproximação em uma menor faixa de temperatura.

Figura 25 - a) Curvas DSC do segundo aquecimento do iPP e de todas as blendas; b) aproximação em uma menor faixa de temperatura. …............................................................... 68

Figura 26 - Curvas tensão vs deformação do iPP e de todas as blendas. 70 


\section{LISTA DE TABELAS}

Tabela 1 - Propriedades do iPP.

Tabela 2 - Valores de $\mathrm{T}_{\mathrm{m}}$ e $\mathrm{T}_{\mathrm{g}}$ para o EVA conforme a variação do teor de VA no copolímero.

Tabela 3 - Comparação de $\mathrm{T}_{\mathrm{m}} \mathrm{e} \mathrm{T}_{\mathrm{g}}$ entre EVOHs com diferentes frações molares de etileno. 36

Tabela 4 - Composição graxa dos óleos vegetais de babaçu, soja e girassol.

Tabela 5 - Propriedades do iPP fornecidas pelo fabricante.

Tabela 6 - Propriedades e teores de VA do EVA65 obtidas por TGA.

Tabela 7 - Denominação das blendas e suas respectivas composições.

Tabela 8 - Solubilidade dos polímeros iPP, EVA65, EVAOH e EVAm em diferentes solventes

Tabela 9 - Programação da temperatura de ensaio de DSC para as amostras de EVA65, EVAOH e EVAm.

Tabela 10 - Programação da temperatura de ensaio de DSC para as amostras de iPP e todas as blendas.

Tabela 11 - Determinação da composição graxa do óleo de babaçu por $\mathrm{RMN}-{ }^{1} \mathrm{H}$; valores experimentais e da literatura. 56

Tabela 12 - Quantidade de reagente, produtos, rendimentos mássicos e taxas de conversão das reações de transesterificação e hidrólise do óleo de babaçu. 58

Tabela 13 - Valores de absorção no espectro de infravermelho para algumas funções orgânicas.

Tabela 14 - $\mathrm{T}_{\text {onset }}$ da primeira etapa de degradação e $\mathrm{T}_{\mathrm{p}}$ de todas as etapas de degradação observadas.

Tabela 15 - Temperaturas de transição vítrea observadas nas curvas DSC dos EVAs. 66

Tabela 16 - Dados do segundo obtidos das curvas do segundo aquecimento para o iPP e suas blendas.

Tabela 17 - Valores de resistência à tração, módulo de elasticidade e elongação do iPP e suas respectivas blendas 



\section{LISTA DE SIGLAS}

\begin{tabular}{|c|c|c|}
\hline PP & - & Polipropileno \\
\hline iPP & - & Polipropileno isotático \\
\hline sPP & - & Polipropileno sindiotático \\
\hline aPP & - & Polipropileno atático \\
\hline EVA & - & Poli(etileno-co-acetato de vinila) \\
\hline EVA65 & - & EVA com $65 \%(\mathrm{~m} / \mathrm{m})$ de acetato de vinila \\
\hline VA & - & Acetato de vinila \\
\hline EVAOH & - & EVA hidrolisado \\
\hline EVAm & - & EVA modificado com ácidos graxos de óleo de babaçu \\
\hline $\mathrm{AGB}$ & - & Ácidos graxos de babaçu \\
\hline FTIR & - & Espectroscopia no Infravermelho por Transformada de Fourier \\
\hline DSC & - & Calorimetria Exploratória Diferencial \\
\hline $\mathrm{RMN}-{ }^{1} \mathrm{H}$ & - & Ressonância Magnética Nuclear de Hidrogênio \\
\hline TGA & - & Termogravimetria \\
\hline DTG & - & Termogravimetria Derivada \\
\hline $\mathrm{T}_{\mathrm{g}}$ & - & Temperatura de transição vítrea \\
\hline $\mathrm{T}_{\mathrm{m}}$ & - & Temperatura de fusão cristalina \\
\hline $\mathrm{T}_{\mathrm{c}}$ & - & Temperatura de cristalização \\
\hline $\mathrm{T}_{\text {onset }}$ & - & Temperatura de início de decomposição \\
\hline $\mathrm{T}_{\mathrm{p}}$ & - & Temperatura de taxa máxima de perda de massa \\
\hline $\mathrm{CaH}_{2}$ & - & Hidreto de cálcio \\
\hline $\mathrm{CDCl}_{3}$ & - & Clorofórmio deuterado \\
\hline $\mathrm{CO}_{2}$ & - & Dióxido de carbono \\
\hline $\mathrm{DMF}$ & - & Dimetilformamida \\
\hline $\mathrm{HCl}$ & - & Ácido clorídrico \\
\hline $\mathrm{KOH}$ & - & Hidróxido de potássio \\
\hline $\mathrm{N}_{2}$ & - & Nitrogênio \\
\hline $\mathrm{NaOH}$ & - & Hidróxido de sódio \\
\hline $\mathrm{O}_{2}$ & - & Oxigênio \\
\hline
\end{tabular}


$\mathrm{SOCl}_{2} \quad-\quad$ Cloreto de tionila

THF - $\quad$ Tetrahidrofurano

TMS - - Tetrametilsilano 


\section{SUMÁRIO}

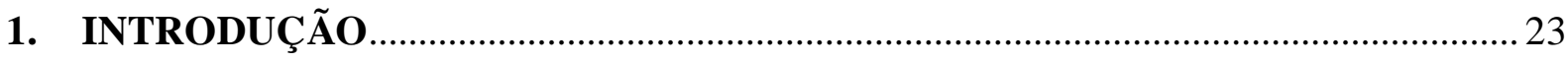

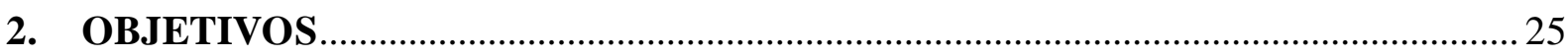

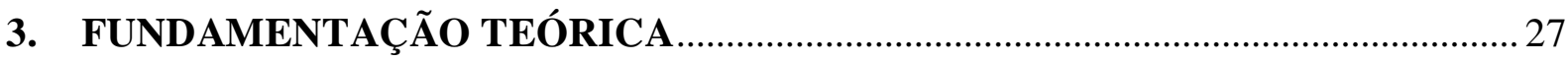

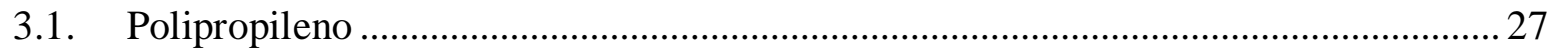

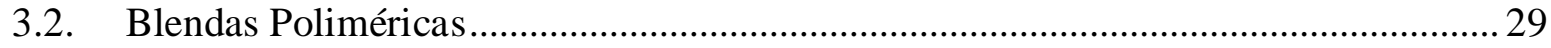

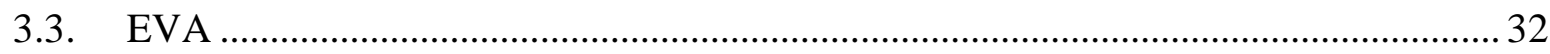

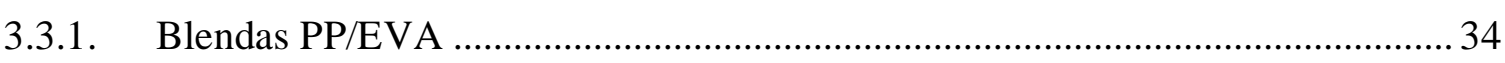

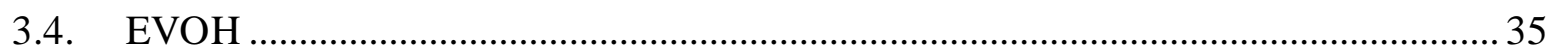

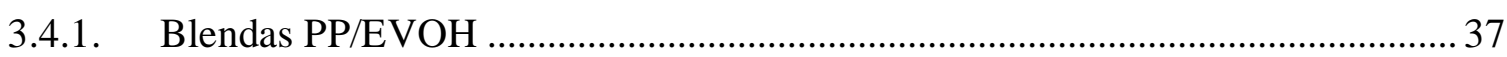

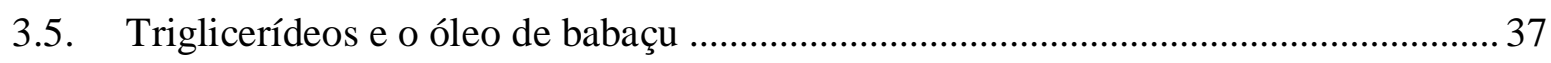

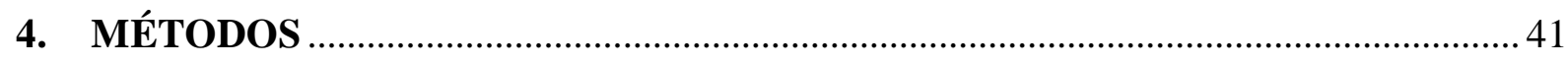

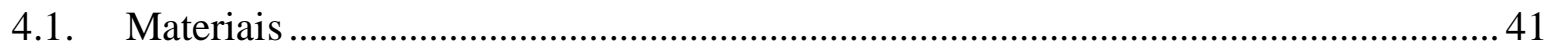

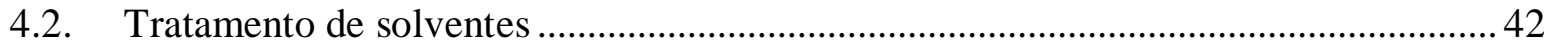

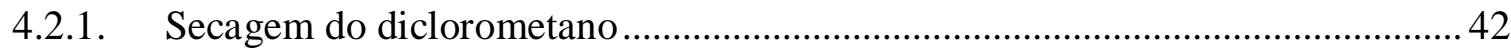

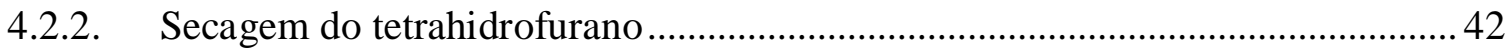

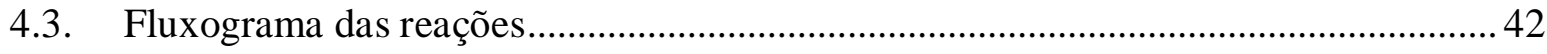

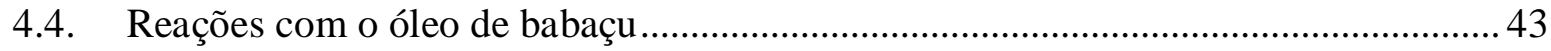

4.4.1. Transesterificação dos triglicerídeos de babaçu ....................................................... 43

4.4.2. Hidrólise dos ésteres metílicos ................................................................................. 44

4.4.3. Ativação do grupo acila - Síntese do cloreto de acila ............................................. 44

4.4.4. Caracterizações por Ressonância Magnética Nuclear de Hidrogênio................... 44

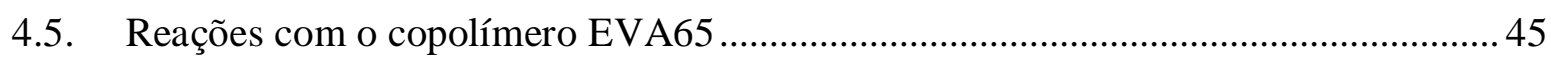

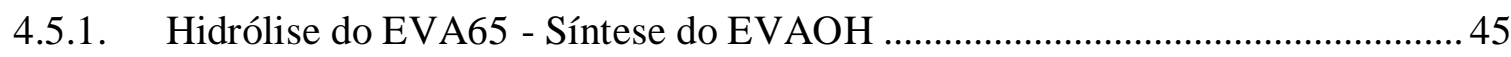

4.5.2. Esterificação do EVAOH - Síntese do EVAm ................................................... 45

4.5.3. Determinação do grau de hidrólise do EVA65 - Retro-titulação .......................... 45

4.5.4. Caracterização por Espectroscopia no Infravermelho por Transformada de

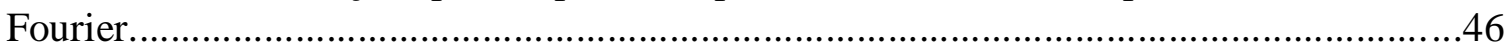

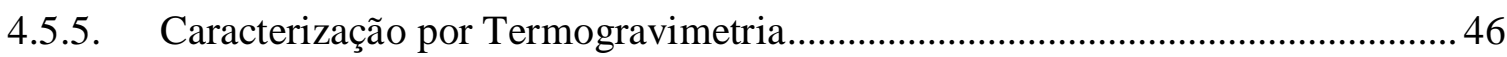

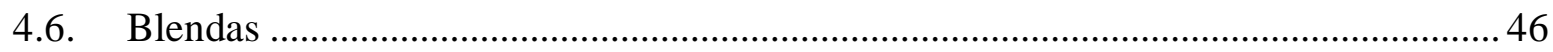

4.6.1. Teste de solubilidade dos polímeros para o preparo das blendas ........................ 47

4.6.2. Caracterização por Calorimetria Exploratória Diferencial .................................... 48

4.6.3. Ensaios mecânicos por tração................................................................................. 49

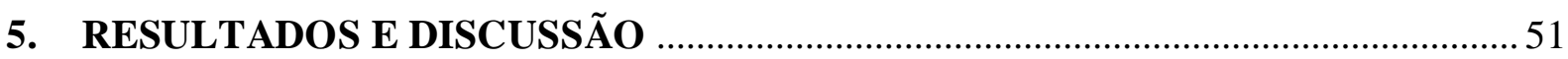

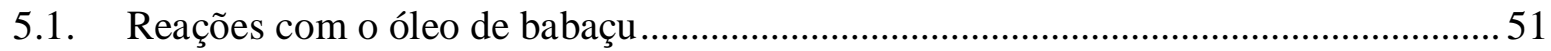


5.1.1. Transesterificação dos triglicerídeos de babaçu ..................................................... 51

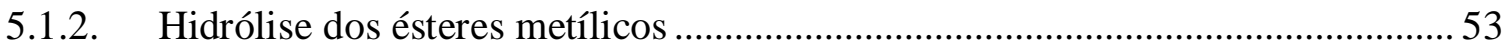

5.1.3. Ativação do grupo acila - Síntese do cloreto de acila ..............................................53

5.1.4. Caracterização do óleo de babaçu e seus produtos por $\mathrm{RMN}-{ }^{1} \mathrm{H}$......................... 54

5.1.4.1. Determinação da composição e da massa molar média.......................................... 54

5.1.4.2. Análise dos ésteres metílicos ............................................................................... 57

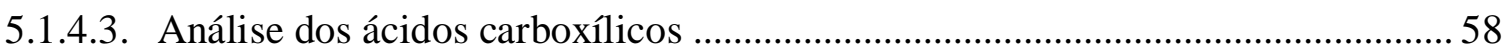

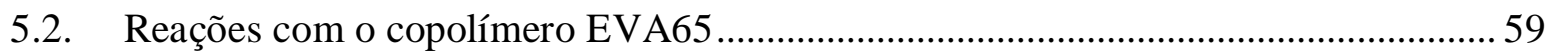

5.2.1. Hidrólise do EVA65 - Esterificação do EVAOH...................................................59

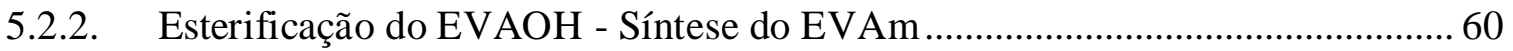

5.2.3. Caracterização do EVA65, EVAOH e EVAm por FTIR ....................................... 60

5.2.4. Caracterização do EVA65, EVAOH e EVAm por TGA ....................................... 62

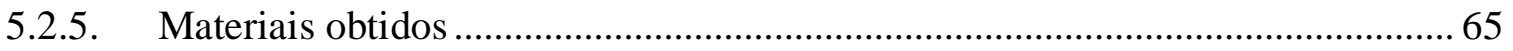

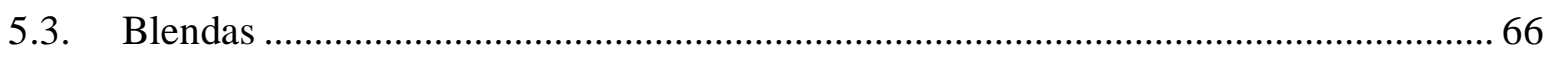

5.3.1. Caracterizações dos polímeros puros e das blendas por DSC ………................... 66

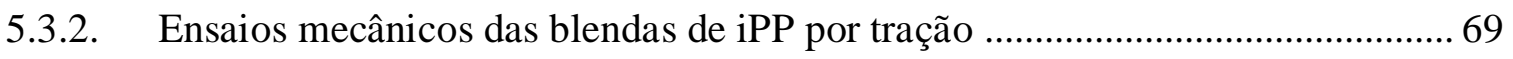

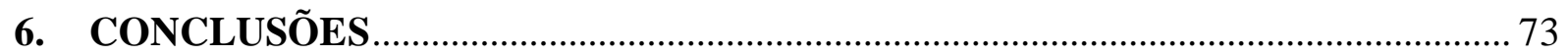

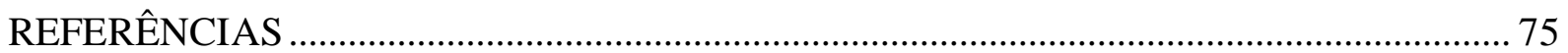




\section{INTRODUÇÃO}

O advento dos catalisadores a base de metais de transição para a polimerização de $\alpha$-olefinas na segunda metade do século XX revolucionou o cenário industrial dos materiais poliméricos. ${ }^{1}$ Em 1953, o pesquisador Karl Ziegler desenvolveu o polietileno de cadeia linear e, no ano seguinte, Giulio Natta protagonizou a síntese do polipropileno isotático (iPP). Desde então, o menor custo das $\alpha$-olefinas frente aos monômeros para policondensação, garantiu o domínio das poliolefinas no mercado de termoplástico até os dias de hoje, de forma que os polímeros considerados de alto desempenho passaram a ocupar aplicações específicas e as poliolefinas tornaram-se commodities. ${ }^{2,3}$

Além da facilidade de processamento e baixo custo, o iPP se destaca pela elevada resistência química, térmica e alta rigidez, comparado aos polipropilenos de conformação sindiotática e atática. ${ }^{1}$ Tais propriedades são relacionadas à sua alta cristalinidade e, devido a elas, o iPP tornou-se um dos termoplásticos mais importantes da indústria de polímeros. ${ }^{3}$ No entanto, a sua baixa resistência ao impacto, especialmente em baixas temperaturas, o impede de ser utilizado em aplicações que exijam um alto desempenho mecânico. ${ }^{4}$ Por esta razão, existe um grande interesse científico na alteração das propriedades desse polímero, a fim de se alcançar aquelas observadas em materiais não poliméricos ou plásticos de engenharia. ${ }^{1}$

Nas últimas três décadas, algumas abordagens têm sido investigadas com o objetivo de aumentar a tenacidade de polipropilenos, como a formação de blendas com elastômeros ${ }^{5}$ e a copolimerização com monômeros olefínicos. ${ }^{6}$ Geralmente, o desenvolvimento de blendas se apresenta mais viável economicamente e, nesse contexto, o mecanismo de tenacificação que atua na blenda iPP/elastômero depende do tipo de elastômero, teor, adesão interfacial com a matriz e da morfologia do sistema. O copolímero poli(etileno-co-acetato de vinila), EVA, é um elastômero que pode tenacificar o iPP e tem sido testado em blendas nas últimas décadas. ${ }^{7}$

Neste trabalho, foram desenvolvidas blendas de polipropileno isotático com os seguintes materiais: (I) poli(etileno-co-acetato de vinila) com $65 \%(\mathrm{~m} / \mathrm{m})$ de acetato de vinila, denominado EVA65; (II) poli(etileno-co-álcool vinílico), EVAOH, um copolímero derivado da reação de hidrólise do EVA65; e o (III) EVA modificado, EVAm, obtido através de uma reação de esterificação do EVAOH. A esterificação do EVAOH foi realizada pela inserção de cadeias carbônicas alifáticas, com o intuito de transformar o EVA65 em um copolímero mais apolar. Esta modificação química, de um EVA comercial para um EVA modificado com cadeias graxas saturadas (Figura 1), já foi relatada na literatura com a finalidade de a molécula modificada ser utilizada como inibidor de deposição orgânica para 
dutos de extração de petróleo. ${ }^{8,9}$

Figura 1 - Estruturas químicas hipotéticas dos copolímeros EVA65, com grupos acetato de vinila em azul; EVAOH, com grupos hidroxila em verde; e EVAm, com cadeias graxas em vermelho.

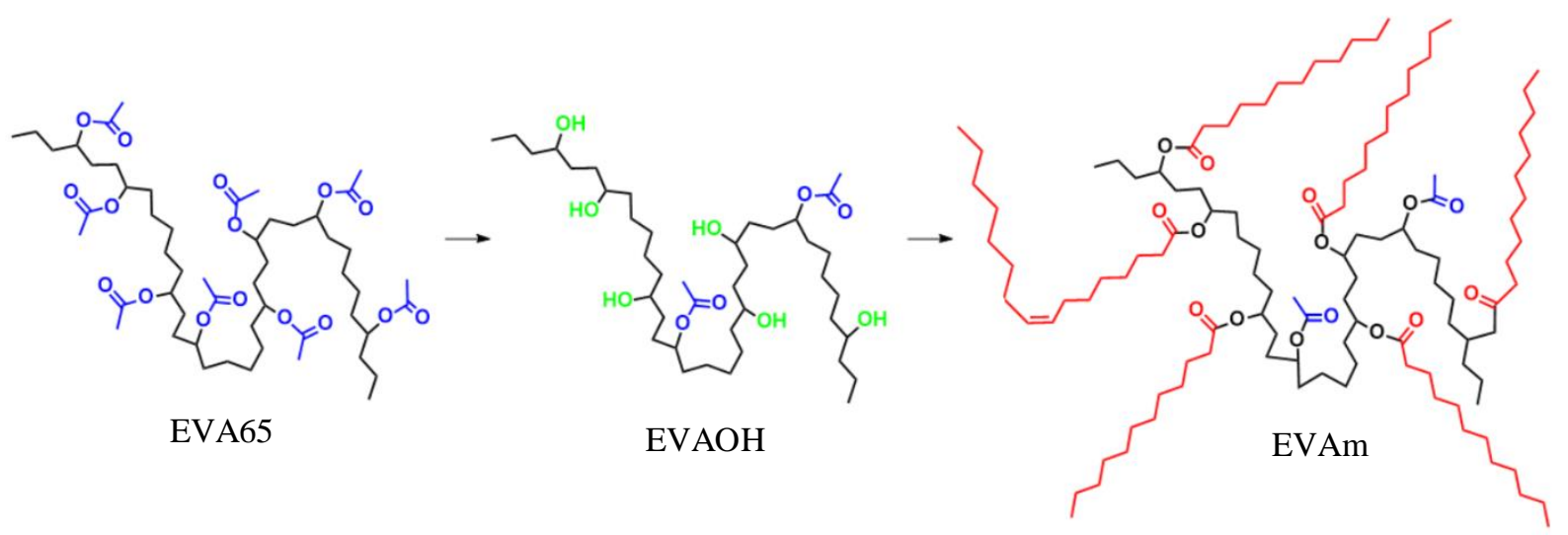

Fonte: Autoria própria.

Com esta alteração química do EVA65, esperava-se que o EVAm fosse mais apolar e que promovesse uma maior interação entre a fase contínua de iPP e as longas cadeias saturadas inseridas, impactando positivamente nas propriedades da blendas iPP/EVAm. 


\section{OBJETIVOS}

Modificar quimicamente o copolímero EVA65 com a incorporação de cadeias carbônicas alifáticas provenientes do óleo de babaçu para aumentar sua apolaridade e promover melhor interação com a fase contínua do iPP, visando aumento da tenacidade e resistência à tração de blendas iPP/EVA.

Os objetivos específicos estão descritos a seguir:

I. Sintetizar os AGB via reação de transesterificação seguida de hidrólise do óleo de babaçu;

II. Produzir o EVAOH pela hidrólise do EVA65 e sintetizar o EVAm por meio da esterificação do EVAOH com os AGB;

III. Preparar blendas iPP/EVA65, iPP/EVAOH e iPP/EVAm nas composições de 5 e $10 \%$ $(\mathrm{m} / \mathrm{m})$ de EVAs;

IV. Avaliar as propriedades térmicas das blendas e dos polímeros sintetizados;

V. Examinar as propriedades mecânicas das blendas e compará-las com as do iPP puro. 


\section{FUNDAMENTAÇÃO TEÓRICA}

\subsection{Polipropileno}

O polipropileno, PP, é uma poliolefina termoplástica obtida através da polimerização, na presença de catalisador sob temperatura e pressão específicas, do monômero de propileno, obtido da destilação fracionada do petróleo (Figura 2). ${ }^{10,11} \mathrm{Na}$ década de 50 , devido ao trabalho de Karl Ziegler e Giulio Natta, o PP ganhou popularidade rapidamente por apresentar características superiores às poliolefinas desenvolvidas até então e por apresentar a densidade mais baixa entre os plásticos commodities. ${ }^{1,3,10}$

Figura 2 - Estruturas químicas do monômero propileno e do polímero polipropileno, respectivamente.

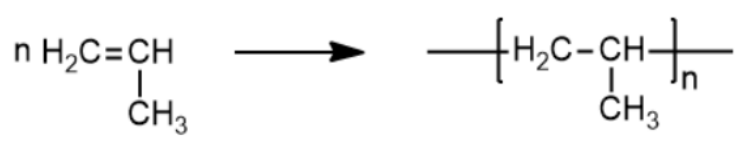

Fonte: Autoria própria.

O PP é amplamente utilizado em todo o mundo devido à sua ampla disponibilidade e baixo custo, tanto do polímero quanto dos monômeros, além disso, é um polímero facilmente processável. ${ }^{2}$ Essas propriedades se devem ao seu comportamento reológico e a resistência à temperatura adequados para a produção e demanda industrial. ${ }^{10}$ Em termos de volume, o PP é o segundo plástico mais produzido mundialmente, depois do polietileno (PE). A produção global de resina de PP foi de 56 milhões de toneladas em 2018 e está projetada para atingir cerca de 88 milhões de toneladas até 2026, crescendo a uma taxa de aproximadamente 5,7 \% ao ano. ${ }^{12}$

Estruturalmente, o PP se assemelha ao PE, porém possui propriedades térmicas e mecânicas superiores, mesmo apresentando densidade menor. Suas propriedades térmicas e mecânicas são superiores entre as poliolefinas para uso à temperatura ambiente. Alta rigidez, baixa densidade, resistência química, térmica e ao impacto, tornam o PP desejável para aplicações industriais. ${ }^{10,13}$ As aplicações do PP são amplas e incluem a produção de fibras, fitas, filmes, folhas, moldagem por injeção e sopro, entre outras. Os setores automotivo e de embalagens têm destaque no uso de polipropileno. ${ }^{14}$

Uma característica incomum do PP, comparada a outros polímeros de maneira geral, é que suas propriedades podem ser alteradas conforme a taticidade da sua cadeia polimérica. Graças ao desenvolvimento dos catalisadores metalocênicos Ziegler-Natta, a simetria de 
adição dos monômeros durante o processo de polimerização pode ser controlada. ${ }^{13,15,16} \mathrm{Em}$ outras palavras, a orientação de cada monômero é controlada durante a formação da cadeia polimérica, permitindo o domínio da estereoquímica, alocando o grupo metil em posições específicas em relação aos outros grupos metil da cadeia. Dessa forma, é possível produzir três tipos de PP: o isotático (iPP), o sindiotático (sPP) e o atático (aPP), ${ }^{15,17}$ representados na Figura 3.

Figura 3 - Estruturas químicas do iPP, do sPP e do aPP, respectivamente.

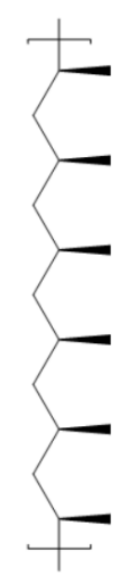

iPP

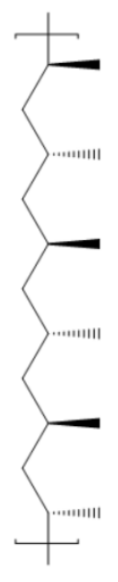

SPP

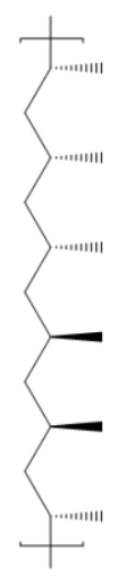

aPP

Fonte: Reproduzido da referência. ${ }^{18}$

O iPP possui um arranjo espacial onde todos os grupos metil estão alocados em um lado da cadeia, o que o torna um material semicristalino com propriedades mecânicas e térmicas superiores em relação aos seus outros isômeros Ainda assim, propriedades como tenacidade e ductilidade caracterizam o iPP como um polímero relativamente frágil a baixas temperaturas. O sPP apresenta os grupos metil em posições alternadas da cadeia polimérica. Devido à distribuição organizada dos grupos metil dessas duas configurações, tanto o iPP quanto o sPP contêm regiões cristalinas e não cristalinas. No entanto, as regiões amorfas do iPP são cristalizáveis e cristalizam lentamente ao longo do tempo. ${ }^{10} \mathrm{~A}$ temperatura de fusão do PP perfeitamente isotático é $171{ }^{\circ} \mathrm{C}$, enquanto que a do sPP (30\% cristalino) é de $130{ }^{\circ} \mathrm{C} .{ }^{13}$ A última configuração, aPP, consiste em um PP com a distribuição aleatória dos grupos metil, resultando em um material totalmente amorfo, com menor rigidez e resistência à temperatura. A Tabela 1 mostra algumas propriedades do polipropileno isotático. ${ }^{14}$ 
Tabela 1 - Propriedades do iPP.

\begin{tabular}{lcc}
\hline Propriedade & Valor & Unidade \\
\hline Temperatura de fusão & $160-166$ & ${ }^{\circ} \mathrm{C}$ \\
Temperatura de transição vítrea & $-3-1$ & ${ }^{\circ} \mathrm{C}$ \\
Resistência a tração & $3.200-5.000$ & $\mathrm{psi}$ \\
Alongamento na ruptura & $3-700$ & $\%$ \\
Absorção de água & 0,01 & $\%$ \\
Densidade & $0,91-0,94$ & $\mathrm{~g} \cdot \mathrm{cm}^{-3}$ \\
Volume específico & $30,4-30,8$ & $\mathrm{~cm}^{3} \cdot \mathrm{Ib}^{-1}$ \\
\hline
\end{tabular}

Fonte: Reproduzido da referência. ${ }^{14}$

O controle das propriedades por meio do domínio da taticidade é uma característica de um grupo selecionado de polímeros. Existem outras maneiras de alterar as propriedades de um material polimérico, como por exemplo, a modificação química do polímero e mistura com outros materiais poliméricos para a formação de blendas poliméricas.

O iPP foi escolhido dentre seus isômeros para a realização deste trabalho porque é o tipo mais comum de PP no mercado e é o mais promissor para melhorias em suas propriedades, visto que estas já são naturalmente superiores comparadas aos polipropilenos sindiotático e atático. ${ }^{1}$

\subsection{Blendas Poliméricas}

De acordo com a IUPAC (International Union of Pure Applied Chemistry), uma blenda polimérica pode ser definida como uma mistura física entre dois ou mais polímeros sem que ocorram ligações químicas primárias entre eles, sendo que as interações secundárias predominam entre as cadeias poliméricas. ${ }^{19}$ Algumas fontes também afirmam que cada componente da mistura deve contribuir com pelo menos $2 \%$ da massa total. ${ }^{20,21}$ A vantagem da produção de blendas é a possibilidade de várias combinações de materiais para a formação de um novo produto de maneira mais econômica em relação à síntese de um novo polímero, podendo obter materiais com características intermediárias ou até superiores às dos polímeros de partida. ${ }^{22}$

Existem diferentes métodos para a produção de blendas, dos quais os principais são a mistura no estado fundido e a mistura por solução. ${ }^{20,23}$ A técnica de mistura no estado fundido é a mais utilizada na indústria, por permitir produção em escalas maiores e por razões 
econômicas. Outra vantagem é que é um método livre de contaminações, pois não utiliza solventes. Esta técnica exige um equipamento denominado extrusora. As matérias-primas são introduzidas na câmara da extrusora onde temperatura, pressão e taxa de cisalhamento são controlados. Cada mistura, levando em conta não só as características intrínsecas das matérias-primas, mas também a composição, tem uma condição de operação específica. Para se obter uma mistura eficiente em uma blenda, essas condições devem ser atendidas. ${ }^{21,24}$

O método de mistura por solução é uma técnica mais simples, muito comum em operações laboratoriais de pequena escala. Nessa técnica, os polímeros são dissolvidos em um solvente comum. Os polímeros são dissolvidos no solvente, geralmente com o aumento da temperatura para aumentar a solubilidade. A mistura permanece em agitação constante para se obter uma blenda homogênea. Ao final da operação, o solvente precisa ser evaporado, seja por temperatura ou pressão reduzida. ${ }^{21,24}$

As blendas poliméricas também podem ser classificadas como miscíveis, imiscíveis ou parcialmente miscíveis. Polímeros termodinamicamente miscíveis misturam-se a nível molecular, portanto formam uma mistura homogênea. Poucas blendas poliméricas se apresentam miscíveis, de forma que normalmente os polímeros formam misturas heterogêneas. Nas blendas miscíveis, as propriedades normalmente são uma média das propriedades dos polímeros de partida, enquanto que nas blendas imiscíveis as propriedades individuais dos componentes permanecem, em certa extensão, dependendo da composição da blenda. Em ambos os tipos de blendas podem ser alcançadas melhorias na propriedade do novo material em relação aos materiais de partida. ${ }^{24,25}$

As blendas imiscíveis podem ser classificadas como compatíveis ou incompatíveis, segundo considerações termodinâmicas. Uma definição comum na literatura é que uma blenda é compatível desde que se alcance uma propriedade útil, de modo que uma blenda pode ser considerada compatível sendo miscível ou imiscível. Já em uma blenda incompatível, as propriedades finais são inferiores às esperadas, ou seja, as interações entre os componentes não modificaram as propriedades da blenda de maneira favorável. ${ }^{25}$

O termo de miscibilidade refere-se à homogeneidade da mistura de polímeros em uma temperatura específica. A miscibilidade pode ser influenciada por vários fatores, como morfologia, interação intermolecular, fase cristalina e tensão superficial, e pode ser avaliada por fatores como a estrutura química, distribuição de massa molar e arquitetura molecular dos componentes. Usando a Segunda Lei da Termodinâmica, pode-se avaliar a miscibilidade ou imiscibilidade de dois polímeros através da Equação 1. ${ }^{24,26}$ 


$$
\Delta G_{m}=\Delta H_{m}-T \Delta S_{m}
$$

onde $\Delta H_{m}$ é a variação de entalpia da mistura, $T$ é a temperatura absoluta e $\Delta S_{m}$ é a variação da entropia. Quando $\Delta G_{m}$ for positivo a blenda será imiscível, indicando que os componentes estão separados em fases puras, para qualquer proporção entre eles. A condição para se obter miscibilidade é o valor negativo de $\Delta G_{m}$ e, que sua derivada segunda em relação à fração volumétrica do segundo componente $\left(\emptyset_{2}\right)$, seja positiva para qualquer composição da mistura, assim como demonstrado na Equação 2. ${ }^{24,27}$

$$
\left(\frac{\partial^{2} \Delta G_{m}}{\partial \varnothing_{2}^{2}}\right)_{T, P}>0
$$

A formação de blendas imiscíveis é mais comum porque as cadeias poliméricas no componente puro se apresentam estáveis e, dificilmente, a entropia sofrerá variação suficiente para gerar miscibilidade. ${ }^{21}$ A variação de entropia pode ser representada pela Equação 3,

$$
\Delta S_{m}=\left(\frac{R V}{V_{R}}\right)\left[\left(\frac{\emptyset_{1}}{x_{1}}\right) \ln \emptyset_{1}+\left(\frac{\emptyset_{2}}{x_{2}}\right) \ln \emptyset_{2}\right]
$$

onde $R$ é a constante dos gases, $V$ é o volume da blenda, $V_{r}$ o volume de referência, $\emptyset_{1}$ é a fração volumétrica do componente 1 e $x_{1}$ é o grau de polimerização do componente 1 . O mesmo se aplica para o segundo componente. A Equação 3 mostra que quanto menor a massa molar, maior a entropia do sistema, favorecendo a miscibilidade, já que menores massas molares possibilitam mais possibilidades de arranjo no sistema. O oposto é observado para massas molares maiores, que tendem para o valor zero $\Delta S_{m}$ e direciona o sistema para a condição de imiscibilidade. Com valores baixos de $\Delta S_{m}$, a miscibilidade fica dependente da variação de entalpia $\Delta H_{m}$ representada na Equação $4,{ }^{21,24}$

$$
\Delta H_{m}=R T\left(\frac{V}{V_{R}}\right) X_{i j} \emptyset_{i} \emptyset_{j}
$$

onde X é a interação adimensional por segmento de polímero.Dessa forma, para o sistema ser miscível é necessário que $\Delta H_{m} \leq 0$. Isso acontece quando há no sistema interações intermoleculares mais fortes, como aquelas dos tipos ligação de hidrogênio e dipolo-dipolo. 
Devido essas interações não serem suficientemente presentes na maioria das blendas, geralmente, estas são termodinamicamente imiscíveis. ${ }^{21}$

\subsection{EVA}

O EVA, Figura 4, é um copolímero aleatório termoplástico transparente, formado por meros de etileno e acetato de vinila (VA). É um copolímero semicristalino, classificado conforme o teor de VA em sua composição, sendo os teores comercialmente mais comuns entre 3 e $50 \%(\mathrm{~m} / \mathrm{m})$ de VA. ${ }^{28-30}$ Porém existem EVAs menos usuais com concentrações superiores de VA. ${ }^{31,32}$

Figura 4 - Estrutura química do copolímero poli(etileno-co-acetato de vinila), EVA, com o mero de etileno em vermelho e o de acetato de vinila em azul.

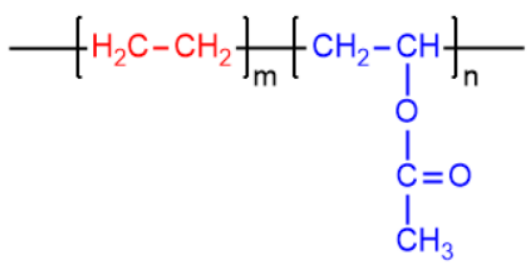

Fonte: Autoria própria.

As propriedades do EVA são determinadas conforme o teor de VA. ${ }^{33-36}$ As ramificações de cadeia curta e a massa molar têm impacto menos significativo sobre as propriedades. ${ }^{28}$ É relatado que o conteúdo de VA de até $10 \%$ é mais transparente, flexível e resistente do que o LDPE (Low Density Polyethylene). ${ }^{30}$ Entre 15 e $30 \%$ de conteúdo VA, os polímeros são macios e flexíveis. Compostos com 30-40 \% VA são macios, elásticos e suas propriedades de resistência e adesão são desejáveis para revestimentos e adesivos. Entre 40 e $50 \%$ VA em EVA tem propriedades semelhantes à borrachas. ${ }^{30}$

Os grupos VA inibem a cristalização dos segmentos da cadeia do PE por meio de impedimento estérico, de forma a impedir o empacotamento dessas cadeias. ${ }^{28,30}$ A Figura 5 ilustra essa propriedade. 
Figura 5 - Ilustração do impedimento estérico causado pelos grupos VA no copolímero EVA; (a) segmentos de cadeia de polietileno empacotados; (b) grupos VA, em azul, afastando as cadeias.

a)

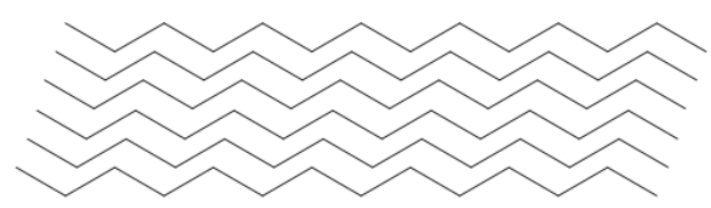

b)

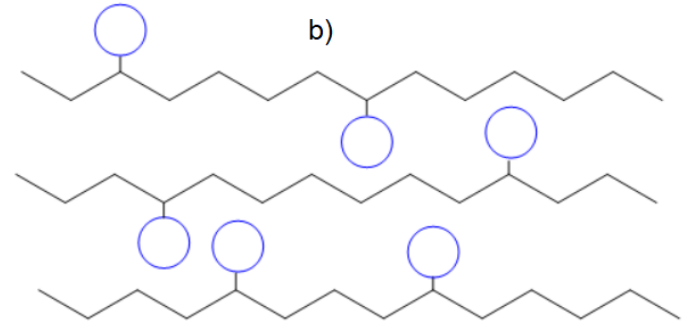

Fonte: Autoria própria.

Dessa forma, os EVAs com conteúdo VA superior a $30 \%(\mathrm{~m} / \mathrm{m})$ são considerados amorfos e o teor VA possibilita a variação da tenacidade e cristalinidade do EVA sem a adição de plastificantes de baixa massa molar. ${ }^{28,30}$ Em relação à morfologia cristalina, o EVA exibe arranjos entre de fase amorfa e cristalina complexos, com pelo menos duas temperaturas de transição vítrea $\left(\mathrm{T}_{\mathrm{g}}\right)$ atribuídas às fases amorfas. ${ }^{37} \mathrm{~A}$ Tabela 2 apresenta os valores de $\mathrm{T}_{\mathrm{m}} \mathrm{e}$ $\mathrm{T}_{\mathrm{g}}$ conforme a variação do teor de VA no copolímero EVA.

Tabela 2 - Valores de $\mathrm{T}_{\mathrm{m}}$ e $\mathrm{T}_{\mathrm{g}}$ para o EVA conforme a variação do teor de VA no copolímero.

\begin{tabular}{lcccc}
\hline $\begin{array}{l}\text { VA em EVA } \\
(\% \text { massa })\end{array}$ & $\begin{array}{c}\mathrm{T}_{\mathrm{m} 1} \\
\left({ }^{\circ} \mathrm{C}\right)\end{array}$ & $\begin{array}{c}\mathrm{T}_{\mathrm{m} 2} \\
\left({ }^{\circ} \mathrm{C}\right)\end{array}$ & $\begin{array}{l}\mathrm{T}_{\mathrm{g} 1} \\
\left({ }^{\circ} \mathrm{C}\right)\end{array}$ & $\begin{array}{c}\mathrm{T}_{\mathrm{g} 2} \\
\left({ }^{\circ} \mathrm{C}\right)\end{array}$ \\
\hline 5 & 50 & 105 & -101 & -35 \\
10 & 53 & 97 & -106 & -36 \\
28 & 46 & 74 & -107 & -38 \\
40 & 38 & 56 & -107 & -34 \\
\hline
\end{tabular}

Fonte: Reproduzido das referências. ${ }^{38,39}$

Um aspecto interessante do EVA é que ele se apresenta como um copolímero anfifílico e pode ser facilmente modificado através da hidrólise dos grupos acetato, transformando-os em grupos hidroxila, tornando o material mais polar conforme o grau de hidrólise. ${ }^{40}$ A Figura 6 apresenta a reação de hidrólise do EVA em solução metanólica de $\mathrm{NaOH}$, resultando em um EVA parcialmente hidrolisado. Uma hidrólise total resulta em um copolímero muito próximo do EVOH. 
Figura 6 - Hidrólise parcial do EVA com solução aquosa de $\mathrm{NaOH}$ resultando em um terpolímero.

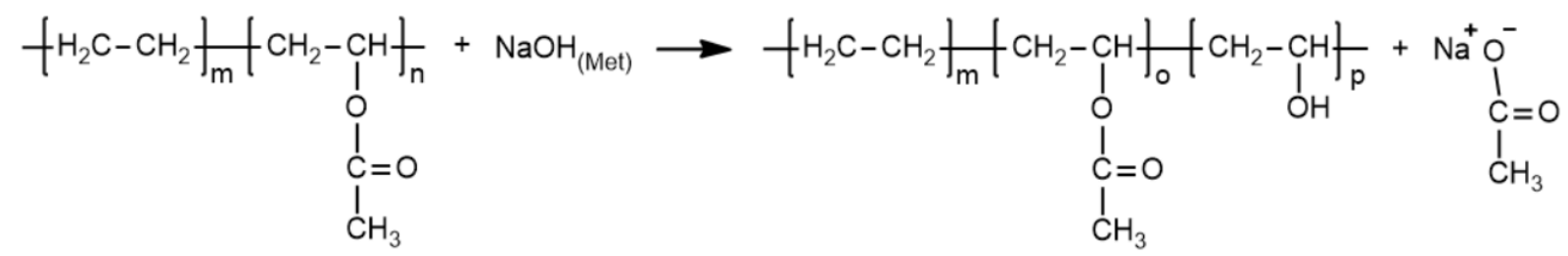

Fonte: Autoria própria.

Neste trabalho o EVA65 foi modificado quimicamente via reação de hidrólise parcial dos seus grupos acetato, de forma que o produto formado consiste em um terpolímero, assim como o representado na Figura 6, acima. Como não foi alcançado $100 \%$ de hidrólise, a denominação do produto escolhida do EVA65 hidrolisado foi EVAOH, pois ainda existe uma baixa concentração do mero acetato de vinila no produto. Como a concentração do mero álcool vinílico é muito superior no $\mathrm{EVAOH}$, suas propriedades são comparáveis ao copolímero EVOH.

\subsubsection{Blendas PP/EVA}

Embora o PP seja amplamente utilizado em muitos campos de aplicações devido às suas propriedades mecânicas e térmicas elevadas frente a outras poliolefinas, sua alta rigidez a baixas temperaturas o torna um material com baixa resistência ao impacto, restringindo a amplitude de suas aplicações. Mesmo à temperatura ambiente, a resistência ao impacto de alguns tipos de PP deixa um amplo espaço para melhorias. Portanto, a melhoria das propriedades do PP é um assunto de grande interesse científico. Blendas de PP com diferentes elastômeros e borrachas, como borracha butílica, copolímeros de etileno-propileno, terpolímeros de etileno-propileno-dieno, poli(isobutileno) e copolímeros de bloco de estirenobutadieno foram produzidas para melhorar a resistência ao impacto do PP, especialmente em baixas temperaturas. Dentre tantas opções, estudos das últimas décadas provaram que o EVA atua como um bom modificador de impacto para o PP. ${ }^{41,42}$

O EVA é um bom modificador de impacto para PP, tanto à temperatura ambiente quanto em baixas temperaturas. Na literatura é relatado que com até $5 \%(\mathrm{~m} / \mathrm{m})$ de um EVA $28 \%$ VA $(\mathrm{m} / \mathrm{m})$ na blenda, a resistência ao impacto aumenta rapidamente. No intervalo de 5 a $30 \%$, aumenta lentamente e, a partir de $30 \%$ volta a aumentar rapidamente. Além disso, quanto maior a porcentagem de VA do EVA, maior é a melhoria da resistência ao impacto. 
Também foi publicado que o EVA aumenta a flexibilidade na blenda, facilitando a mobilidade das cadeias moleculares do PP, aumentando a elongação na ruptura. ${ }^{41-43}$

Neste trabalho, optou-se por utilizar o EVA com $65 \%(\mathrm{~m} / \mathrm{m})$, um material incomum na literatura, devido ao seu alto teor de acetato de vinila. Essa escolha é justificada pelo fato das funcionalizações com as cadeias graxas do óleo de babaçu justamente na função hidroxila alcançada pela hidrólise do EVA, ou seja, quanto mais acetato de vinila na composição do EVA, mais sítios para a funcionalização estarão disponíveis após o processo de hidrólise.

\subsection{EVOH}

O EVOH é um copolímero semi-cristalino de sequência aleatória. Esse copolímero pode ser obtido através da transesterificação ou da hidrólise de copolímeros aleatórios de EVA, onde o grupo acetato de vinila é transformado em grupos hidroxila (-OH), formando o mero de álcool vinílico. ${ }^{30,44-46}$ As reações de transesterificação e hidrólise do EVA estão representadas a seguir na Figura 7.

Figura 7 - Síntese do EVOH por dois processos diferentes: (a) transesterificação do EVA com metanol, e (b) hidrólise do EVOH com solução aquosa de $\mathrm{NaOH}$.

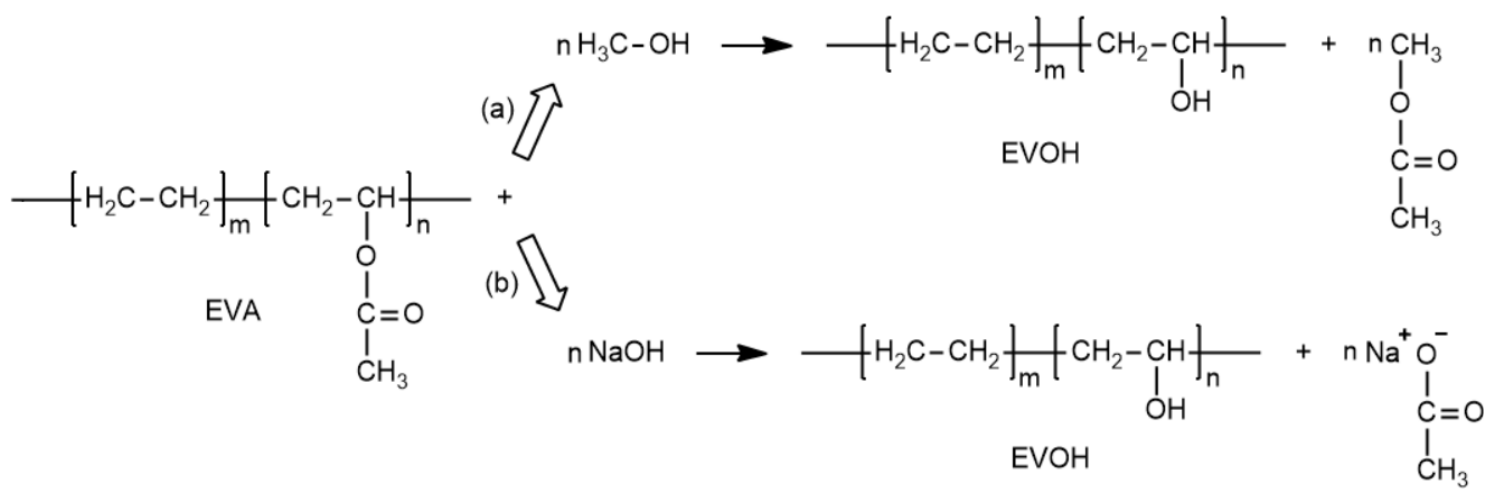

Fonte: Autoria própria.

O EVOH ganhou reconhecimento por suas propriedades de barreira contra gases, como oxigênio, dióxido de carbono e nitrogênio. Em especial, sua excelente barreira ao oxigênio tornou o EVOH um dos materiais de barreira de gases mais comumente usados em embalagens de alimentos. Tais propriedades são atribuídas pelas fortes interações intermoleculares dos grupos hidroxila dos alcoóis vinílicos, através das ligações de hidrogênio. ${ }^{44,47}$ 
Os copolímeros de EVOH são classificados pela fração molar de etileno. As composições comercialmente mais comuns variam entre 27 e $48 \%$ (mol) de etileno. ${ }^{48,49}$ Existem composições superiores tanto de $\mathrm{EVOH}$ quanto de EVA, ${ }^{31}$ que pode ser hidrolisado para se obter um EVOH de alto teor de álcool vinílico.

Por ser um copolímero, a composição do EVOH dita suas propriedades. Os alcoóis vinílicos, por exemplo, são responsáveis pelas propriedades excepcionais de barreira ao gás, porém são solúveis em água e são conhecidas pela dificuldade de processamento. No entanto, os etilenos exibem boa resistência à água, devido seu caráter hidrofóbico e apresentam também propriedades de barreira contra gases. ${ }^{47,50,51} \mathrm{~A}$ barreira de oxigênio, por exemplo, melhora com menor teor de etileno. Já a $\mathrm{T}_{\mathrm{g}}$ e a $\mathrm{T}_{\mathrm{m}}$ diminuem com o aumento do teor de etileno, tornando o polímero menos quebradiço e mais fácil de processar. ${ }^{44}$ A Tabela 3 apresenta a variação das temperaturas de fusão e de transição vítrea entre diferentes EVOHs de acordo com sua composição.

Tabela 3 - Comparação de $\mathrm{T}_{\mathrm{m}}$ e $\mathrm{T}_{\mathrm{g}}$ entre EVOHs com diferentes frações molares de etileno

\begin{tabular}{lcc}
\hline $\begin{array}{l}\text { Etileno em EVOH } \\
(\% \text { molar })\end{array}$ & $\begin{array}{c}\mathrm{T}_{\mathrm{m}} \\
\left({ }^{\circ} \mathrm{C}\right)\end{array}$ & $\begin{array}{c}\mathrm{T}_{\mathrm{g}} \\
\left({ }^{\circ} \mathrm{C}\right)\end{array}$ \\
\hline 27 & 190 & 63 \\
32 & 183 & 60 \\
38 & 172 & 56 \\
44 & 165 & 53 \\
48 & 157 & 50 \\
\hline
\end{tabular}

Fonte: Reproduzido da referência. ${ }^{44}$

O grau de cristalinidade do EVOH também está relacionado à sua composição. Esse copolímero apresenta uma matriz amorfa com fase cristalina dispersa. Composições com teores de álcool vinílico inferiores a $20 \%$ (molar) apresentam um material com estrutura cristalina ortorrômbica, semelhante ao PE. Entre 20 a 60 \% (molar), a estrutura observada é a pseudo-hexagonal. Quando maior que $60 \%$ (molar), os cristais são monoclínicos, assim como o poli(álcool vinílico), PVOH. ${ }^{44,52-54}$ 


\subsubsection{Blendas PP/EVOH}

Os estudos acerca das blendas PP/EVOH, em sua maioria, não são focados na melhoria das propriedades térmicas e mecânicas do PP, mas sim nas suas propriedades de barreira, para diversos usos, principalmente no setor de embalagens. ${ }^{55-58}$

As blendas $\mathrm{PP} / \mathrm{EVOH}$ têm um grande interesse para a indústria de embalagens como camadas de barreira para proteger os alimentos pela ação do oxigênio e da umidade e, consequentemente, aumentar a vida útil tanto dos alimentos quanto da própria da embalagem. Essas blendas combinam a boa processabilidade do PP e as excelentes propriedades de barreira do copolímero EVOH. O PP é um polímero commodity com boas propriedades mecânicas e de barreira à água. Por outro lado, o EVOH é um copolímero com propriedades de barreira a gases como $\mathrm{O}_{2}$ e $\mathrm{CO}_{2}$ e tem alta resistência aos hidrocarbonetos. $\mathrm{O}$ EVOH também é altamente sensível à umidade, o que altera sua resistência à permeação de oxigênio. ${ }^{55-57}$

Foi relatado na literatura que a adição de uma pequena quantidade de EVOH em uma matriz de PP pode levar a um produto de baixo custo com propriedades de barreira muito melhoradas. Blendas com $20 \%(\mathrm{~m} / \mathrm{m})$ de EVOH com $32 \%$ de etileno (molar), resultaram em um material com permeabilidade até sete vezes mais baixas que o PP puro. Quanto às propriedades mecânicas, para baixas concentrações de EVOH, são muito semelhantes ao PP puro. Porém, com o aumento da concentração de EVOH, as blendas apresentam maior rigidez e o alongamento na ruptura atinge valores menores. O mesmo é observado para EVOHs com concentrações maiores de álcool vinílico. ${ }^{55-57}$

\subsection{Triglicerídeos e o óleo de babaçu}

Os óleos vegetais são compostos principalmente por triglicerídeos e ácidos graxos. ${ }^{59}$ Diferenciam-se das gorduras por se apresentarem na forma líquida a $25{ }^{\circ} \mathrm{C}$, sendo extraídos dos frutos ou sementes de diversas plantas oleaginosas. ${ }^{59}$ Sua composição é complexa, pois existem vários tipos de ácidos graxos, que por sua vez, formam diferentes tipos de triglicerídeos. ${ }^{60,61}$

Os ácidos graxos são ácidos carboxílicos com longas cadeias carbônicas. ${ }^{59}$ São diferenciados de acordo com a quantidade de átomos de carbono e grupos funcionais, como insaturações e hidroxilas. Geralmente possuem de 12 a 18 átomos de carbono, podendo ser 
mono ou poli-insaturados. ${ }^{59,61}$ A estrutura molecular de alguns tipos de ácidos graxos estão ilustrados na Figura 8.

Figura 8 - Estrutura molecular de alguns ácidos graxos comuns em triglicerídeos.<smiles>CC(C)(C)C(=O)O</smiles>

Ácido caproico<smiles>CC(C)(C)C(=O)O</smiles>

Ácido láurico<smiles>CC(C)(C)C(=O)O</smiles>

Ácido esteárico<smiles>CC(CC=CC(C)(C)C)C(=O)O</smiles>

Ácido oleico<smiles>CC(CC=CCC=CC(C)(C)C)C(=O)O</smiles>

Ácido linoleico<smiles>CC(C)(C)C(O)C/C=C/CC(=O)O</smiles>

Ácido ricinoleico

Fonte: Autoria própria.

Os triglicerídeos consistem em três ácidos graxos, em qualquer combinação, esterificados a uma molécula de glicerol. ${ }^{59}$ A estrutura química de um triglicerídeo genérico está representada na Figura 9.

Figura 9 - Estrutura de um triglicerídeo genérico composto por três ácidos graxos diferentes esterificados a uma molécula de glicerol, em azul.

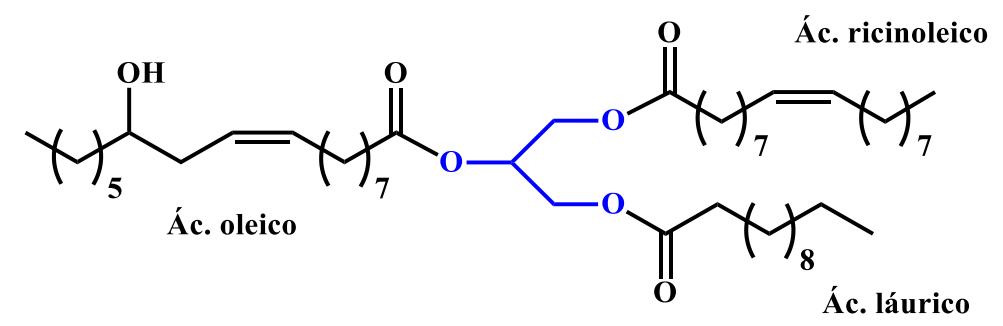

Fonte: Autoria própria.

Como citado anteriormente, a composição graxa dos óleos vegetais é complexa e pode variar bastante dependendo do fruto ou semente oleaginosa do qual foi extraído. A Tabela 4 mostra a composição graxa de alguns óleos comuns no Brasil: ${ }^{60,62}$

O Brasil possui um vasto território que abrange diferentes tipos de solo e clima, o que favorece a diversificação da atividade agrícola, tanto no cultivo extensivo quanto no aproveitamento de culturas de ocorrência natural (extrativismo). ${ }^{63}$ 
Tabela 4 - Composição graxa dos óleos vegetais de babaçu, soja e girassol.

\begin{tabular}{lccc}
\hline Ácidos graxos & $\begin{array}{c}\text { Óleo de babaçu } \\
(\%)\end{array}$ & $\begin{array}{c}\text { Óleo de soja } \\
(\%)\end{array}$ & $\begin{array}{c}\text { Óleo de girassol } \\
(\%)\end{array}$ \\
\hline Caproico (6:0) & 3,3 & nd & nd \\
Caprílico (8:0) & 9,2 & nd & nd \\
Cáprico (10:0) & 9,6 & nd & nd \\
Láurico (12:0) & 54,7 & nd & nd \\
Mirístico (14:0) & 11,8 & 0,4 & nd \\
Palmítico (16:0) & 4,8 & 10,9 & 6,7 \\
Esteárico (18:0) & 2,1 & 3,2 & 4,5 \\
Oleico (18:1) & 6,5 & 24 & 21 \\
Linoleico (18:2) & 0,9 & 54,5 & 68 \\
Linolênico (18:3) & nd & 6,9 & nd \\
Ricinoleico (18:1 + OH) & nd & nd & nd \\
\hline Composição saturada & 90,6 & 14,7 & 11 \\
Composição insaturada & 9,4 & 85,3 & 89 \\
\hline
\end{tabular}

a $(18: 1+\mathrm{OH})$ lê-se: cadeia com 18 carbonos; 1 insaturação; grupo funcional hidroxila.

${ }^{\mathrm{b}}$ nd: não determinado.

Fonte: Reproduzido das referências. ${ }^{60,62}$

Dentre os óleos citados na Tabela 4, o óleo de babaçu é o mais peculiar, pois apresenta cerca de $90 \%$ de composição graxa saturada, majoritariamente láurica. Este óleo provém da palmeira de babaçu, uma espécie adaptada às áreas Norte e Nordeste do Brasil. ${ }^{64}$ Trata-se de uma árvore de grande porte que pode chegar aos 30 metros de altura, cujos frutos, cocos de babaçu, possuem amêndoas em seu interior, de onde é extraído o óleo. A amêndoa corresponde de 6 a $8 \%$ do peso do coco e contêm entre 60 a $68 \%$ de óleo, podendo chegar a $72 \%$ em condições favoráveis de crescimento da palmeira. ${ }^{65}$

A escolha do óleo de babaçu para o projeto se deu pelo fato de ser uma fonte de baixo custo e renovável de graxos alifáticos saturados, em sua maioria, além de ser abundante no Brasil. Uma nova aplicação para o óleo também pode agregar valor ao coco de babaçu, uma vez que a extração das amêndoas é uma tarefa complementar à renda de milhares de famílias e a remuneração por este trabalho é muito baixa. ${ }^{64}$ 


\section{MÉTODOS}

\subsection{Materiais}

Os materiais utilizados neste trabalho foram: (I) polipropileno isotático homopolímero HP500N, produzido pela Braskem. Esse polipropileno é considerado de média fluidez e elevada rigidez, denominado iPP neste trabalho; (II) óleo de babaçu refinado produzido pela Destilaria Bauru. Trata-se de um óleo de babaçu extraído com solventes orgânicos que posteriormente são evaporados, esta técnica de refino (extração por solventes) aumenta o rendimento de extração, diminuindo o custo, porém direciona o produto para fins não alimentícios; e (III) EVA Levamelt 650, um copolímero aleatório de etileno e acetato de vinila com teor de $65 \%(\mathrm{~m} / \mathrm{m})$ de VA, gentilmente cedido pela Lanxess do Brasil. Esse copolímero foi denominado ao longo deste trabalho como EVA65.

A Tabela 5 apresenta propriedades físicas mecânicas e térmicas do iPP fornecidas pelo fabricante.

Tabela 5 - Propriedades do iPP fornecidas pelo fabricante.

\begin{tabular}{lcc}
\hline Propriedades & iPP & Unidades \\
\hline Densidade relativa & 0,905 & g.cm \\
Resistência à tração no escoamento & 36 & $\mathrm{MPa}$ \\
Alongamento no escoamento & 9 & $\%$ \\
Resistência ao impacto Izod a $23^{\circ} \mathrm{C}$ & 30 & $\mathrm{~J}^{-1}$ \\
\hline
\end{tabular}

Fonte: Reproduzido da referência. ${ }^{66}$

A Tabela 6 apresenta propriedades físicas e os teores de VA do EVA65 ${ }^{32}$.

Tabela 6 - Propriedades e teores de VA do EVA65 obtidas por TGA.

\begin{tabular}{lcc}
\hline Propriedades & EVA65 & Unidades \\
\hline Densidade relativa & 1,05 & g.cm \\
Temperatura de transição vítrea & -20 & ${ }^{\circ} \mathrm{C}$ \\
Teor nominal de VA & 65,0 & $\%(\mathrm{~m} / \mathrm{m})$ \\
Teor medido de VA & 66,7 & $\%(\mathrm{~m} / \mathrm{m})$ \\
\hline
\end{tabular}

Fonte: Reproduzido da referência. ${ }^{32}$ 
Foram utilizados os solventes diclorometano, tetrahidrofurano, metanol e acetato de etila grau HPLC Honeywell. Sódio metálico 99,9\%, benzofenona 99,0 \%, hidreto de cálcio 95,0 \%, cloreto de tionila 99,0 \% e N,N-dimetilformamida 99,8 \% Sigma Aldrich. Piridina 99,5 \% e anidrido acético 98,0 \% Merck. Hidróxido de potássio 85,0 \%, Hidróxido de sódio 98,0 \% e HCl 37 \% P.A. Synth. Argônio 5.0 e nitrogênio 4,8 White Martins.

\subsection{Tratamento de solventes}

\subsubsection{Secagem do diclorometano}

Um balão de 3 vias de $1 \mathrm{~L}$ foi acoplado a um sistema de refluxo com fluxo de argônio seco. Ao balão foi adicionado $250 \mathrm{~mL}$ de $\mathrm{CH}_{2} \mathrm{Cl}_{2}$ e $3,0 \mathrm{~g}$ de $\mathrm{CaH}_{2}$. O sistema foi mantido à temperatura ambiente sob intensa agitação magnética overnight, posteriormente, o solvente foi refluxado por $3 \mathrm{~h}$ e então, destilado e recolhido. Um pequeno volume inicial é separado, pois pode haver impurezas e água.

\subsubsection{Secagem do tetrahidrofurano}

Utilizou-se o mesmo sistema da secagem do $\mathrm{CH}_{2} \mathrm{Cl}_{2}$, porém com um balão de 3 vias de 2 L. Foi adicionado ao balão, 1 L de THF e aparas de sódio metálico e benzofenona. Manteve-se o sistema sob refluxo e forte agitação magnética até que a solução amarelopálido, devido a adição de benzofenona, se torna azul-escuro, indicando a ausência de água do solvente. Em seguida o solvente foi destilado.

\subsection{Fluxograma das reações}

A parte experimental deste trabalho foi dividida em três etapas principais: (I) Reações com o óleo de babaçu; (II) Reações com o copolímero EVA65; e (III) Blendas. Essas etapas estão representadas no fluxograma a seguir (Figura 10). 
Figura 10 - Fluxograma da parte experimental.

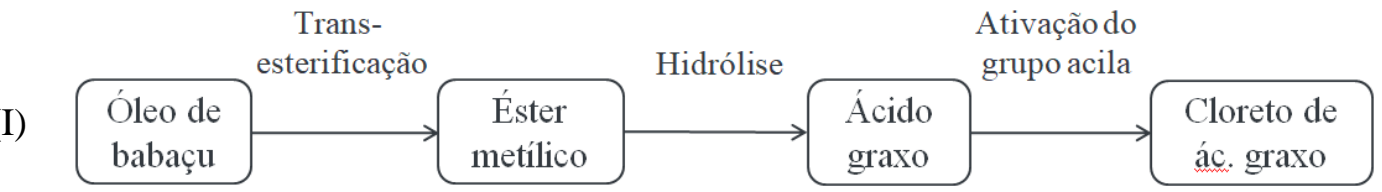

(II)

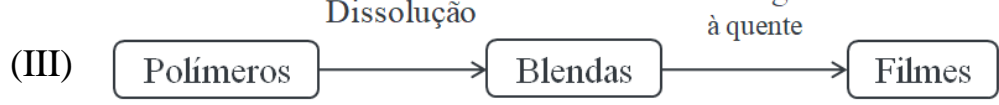

Fonte: Autoria própria.

As etapas (I), (II) e (III) do fluxograma são abordadas nos subitens seguintes 4.4, 4.5 e 4.6 , respectivamente.

\subsection{Reações com o óleo de babaçu}

\subsubsection{Transesterificação dos triglicerídeos de babaçu}

Uma solução alcoólica de $\mathrm{KOH}$ foi preparada dissolvendo-se 0,36 g de $\mathrm{KOH}$ em $7 \mathrm{~mL}$ de metanol até a dissolução completa do $\mathrm{KOH}$. Em seguida, 18,0 g de óleo de babaçu foram aquecidos a $45^{\circ} \mathrm{C}$ em um balão de fundo redondo de duas vias em um sistema de refluxo e então foi adicionada a solução alcoólica previamente preparada. O sistema foi mantido a $45^{\circ} \mathrm{C}$, sob forte agitação durante 1,5 h. ${ }^{67-69}$ Ao final da reação, a solução foi acidificada com $\mathrm{HCl}$, em seguida, a solução foi transferida para um funil de separação, no qual foi observada a formação de duas fases. Ao funil foi adicionado $20 \mathrm{~mL}$ de acetato de etila para auxiliar na extração da fase orgânica. Posteriormente a solução foi lavada três vezes com água destilada para a remoção de sais. A fase orgânica foi recolhida e os solventes remanescentes foram extraídos em um rotaevaporador. O produto final, ésteres metílicos, foi pesado $(17,50 \mathrm{~g})$ e foram realizadas análises de $\mathrm{RMN}-{ }^{1} \mathrm{H}$. 


\subsubsection{Hidrólise dos ésteres metílicos}

Foi preparada uma solução aquosa $6 \mathrm{M}$ de $\mathrm{NaOH}$ solubilizando-se 12,0 g de $\mathrm{NaOH}$ em $50 \mathrm{~mL}$ de água destilada. Esta solução foi vertida em 15,0 g de ésteres metílicos em um balão de fundo redondo de uma via acoplado a um sistema de refluxo a $100{ }^{\circ} \mathrm{C}$ durante $4 \mathrm{~h}$ sob forte agitação. ${ }^{70} \mathrm{Em}$ seguida, a solução foi acidificada com $\mathrm{HCl}$ concentrado e transferida para um funil de separação. Ao funil foram adicionados $20 \mathrm{~mL}$ de acetato de etila para facilitar a extração da fase orgânica. A solução foi lavada três vezes com água destilada para a remoção de sais. A fase orgânica foi separada e os solventes foram eliminados por rotaevaporação. O produto, ácidos graxos de babaçu, foi pesado $(11,93 \mathrm{~g})$ e foram realizadas análises de $\mathrm{RMN}-{ }^{1} \mathrm{H}$. A etapa de transesterificação 4.3 .1 foi previamente realizada para facilitar a extração do glicerol na fase aquosa, pois em uma hidrólise direta há a formação de emulsão, o que dificulta a extração dos ésteres metílicos, consequentemente, diminui o rendimento da reação.

\subsubsection{Ativação do grupo acila - Síntese do cloreto de acila}

Em um balão de $25 \mathrm{~mL}$ de duas vias sob fluxo de argônio foi adicionado 1,37 $\mathrm{g}$ de AGB e 3,0 mL de $\mathrm{CH}_{2} \mathrm{Cl}_{2}$ seco. $\mathrm{O}$ sistema foi resfriado em banho de gelo e, em seguida, adicionou-se $0,45 \mathrm{~mL}$ de $\mathrm{SOCl}_{2}$ e $0,04 \mathrm{~mL}$ de DMF. A solução permaneceu sob forte agitação magnética por 15 minutos em banho de gelo e por $12 \mathrm{~h}$ à temperatura ambiente. $\mathrm{O}$ solvente e excesso de $\mathrm{SOCl}_{2}$ foram removidos sob pressão reduzida utilizando-se um trap com $\mathrm{N}_{2}$ líquido.

\subsubsection{Caracterizações por Ressonância Magnética Nuclear de Hidrogênio}

As reações com o óleo de babaçu foram caracterizadas por Ressonância Magnética Nuclear de Hidrogênio (RMN-1 H). Os espectros de $\mathrm{RMN}-{ }^{1} \mathrm{H}$ foram obtidos no espectrômetro Agilent Technologies 500/54/ASP, localizado no Instituto de Química de São Carlos (IQSC). Todas as amostras foram dissolvidas em $\mathrm{CDCl}_{3} \mathrm{e}$ os ensaios foram realizados à temperatura ambiente, com pulso de $45^{\circ}$, tempo de espera de 3,14 segundos e foi utilizado TMS como referência. 


\subsection{Reações com o copolímero EVA65}

\subsubsection{Hidrólise do EVA65 - Síntese do EVAOH}

Foi montado um sistema de refluxo com fluxo de $\mathrm{N}_{2}$ utilizando-se um balão de $1 \mathrm{~L}$ de duas vias, ao qual foi adicionado 25,0 g de EVA65 e $150 \mathrm{~mL}$ THF. O sistema foi mantido por $1 \mathrm{~h}$ a $50{ }^{\circ} \mathrm{C}$ sob agitação magnética e então foi adicionada $60 \mathrm{~mL}$ de solução metanólica de $\mathrm{NaOH}$ 0,5 M, ${ }^{30,31}$ utilizando-se uma pipeta volumétrica. Manteve-se o sistema nas condições citadas por 6 h e, após o arrefecimento, foi adicionado $\mathrm{HCl}$ 1,0 M até atingir o pH 5,0.

A solução, agora turva (branca), foi vertida vagarosamente em $4 \mathrm{~L}$ de água destilada gelada. O EVA65 hidrolisado $(\mathrm{EVAOH})$ precipitou imediatamente, formando um polímero branco, que foi lavado com água destilada corrente e depois seco sob vácuo e temperatura de $80{ }^{\circ} \mathrm{C}$ por 24 h. Após seco, o polímero foi pesado (17,50 g) e guardado em dessecador.

\subsubsection{Esterificação do EVAOH - Síntese do EVAm}

A um balão de $50 \mathrm{~mL}$ de três vias acoplado em um sistema de refluxo e fluxo de argônio seco, foi adicionado 0,5 g de EVAOH e 10, $\mathrm{mL}$ de tolueno seco. O sistema permaneceu sob agitação magnética a $65{ }^{\circ} \mathrm{C}$ por $24 \mathrm{~h}$ para promover melhor interação do polímero com o solvente. Após tempo de contato (o EVOH não atingiu a dissolução), foi adicionado $0,01 \mathrm{~mL}$ de piridina, destinadas a reagir com o $\mathrm{HCl}$ formado durante a reação. Em seguida, a solução de cloreto de acila foi lentamente, via cânula, utilizando-se fluxo de argônio seco. A temperatura do sistema foi elevada a $85{ }^{\circ} \mathrm{C}$ e foi mantida sob agitação vigorosa por $3 \mathrm{~h} .{ }^{8} \mathrm{O}$ copolímero formado foi precipitado em álcool etílico, filtrado e seco a $80{ }^{\circ} \mathrm{C}$ sob pressão reduzida.

\subsubsection{Determinação do grau de hidrólise do EVA65 - Retro-titulação}

Os teores de hidroxila do EVA hidrolisado, o EVAOH, foram determinados pela retrotitulação do anidrido acético em excesso na presença de piridina. Neste procedimento, ${ }^{30} 1,0 \mathrm{~g}$ de EVAOH foi dissolvido em $25 \mathrm{~mL}$ de tolueno em um sistema de refluxo a $115{ }^{\circ} \mathrm{C}$. Em seguida, 5,0 $\mathrm{mL}$ de uma mistura de anidrido acético e piridina 70:30 \% (m/m) foi adicionada ao sistema utilizando-se uma pipeta volumétrica. O refluxo foi mantido por $24 \mathrm{~h}$ e então se adicionou $5 \mathrm{~mL}$ de água destilada pelo condensador e o aquecimento continua por mais 10 
minutos. O sistema esfria à temperatura ambiente por $1 \mathrm{~h}$ e se adiciona $15 \mathrm{~mL}$ de $\mathrm{n}$-butanol pelo condensador para lavá-lo. A solução final é titulada com $\mathrm{KOH} 0,5 \mathrm{M}$ padronizado utilizando-se fenolftaleína como indicador. O processo foi feito em duplicata, assim como o branco.

\subsubsection{Caracterização por Espectroscopia no Infravermelho por Transformada de Fourier}

Os copolímeros EVA65, EVAOH e EVAm foram caracterizados por meio de análises de Espectroscopia no Infravermelho por Transformada de Fourier (FTIR). Os espectros foram obtidos no IQSC por meio do espectrofotômetro Iraffinity, produzido pela Shimadzu, equipado com um acessório de reflectância atenuada com cristal de seleneto de zinco recoberto com filme de ouro de três reflexões. Os ensaios foram realizados na faixa espectral de 600 a $4.000 \mathrm{~cm}^{-1}, 32$ scans, com resolução de $4 \mathrm{~cm}^{-1}$. Foram utilizadas amostras com espessura de aproximadamente $0,15 \mathrm{~mm}$ elaboradas em uma prensa hidráulica com controle de temperatura e pressão.

\subsubsection{Caracterização por Termogravimetria}

Tanto o EVA65 quanto os produtos obtidos a partir desse copolímero, o EVAOH e o EVAm, foram analisados por Termogravimetria (TGA). As curvas TGA e DTG foram obtidas pelo equipamento Perkin Elmer, modelo Pyris 1 TGA, localizado no Departamento de Engenharia de Materiais da EESC-USP. Os ensaios foram realizados no intervalo de temperatura de 25 a $600{ }^{\circ} \mathrm{C}$, utilizando um cadinho de platina. A taxa de aquecimento foi de $10{ }^{\circ} \mathrm{C} \mathrm{min}^{-1}$, sob atmosfera de $\mathrm{N}_{2}$ com fluxo de $40 \mathrm{~mL} \cdot \mathrm{min}^{-1}$. A massa das amostras utilizadas foi de aproximadamente de $20 \mathrm{mg}$.

\subsection{Blendas}

Foram preparadas blendas iPP/EVA, iPP/EVAOH e iPP/EVAm em duas composições, 5 e $10 \%(\mathrm{~m} / \mathrm{m})$ de cada polímero na matriz iPP. Essas porcentagens foram escolhidas baseadas em relatos da literatura, onde já foi observado que até $5 \%(\mathrm{~m} / \mathrm{m})$ de um EVA $28 \%$ VA $(\mathrm{m} / \mathrm{m})$ na blenda iPP/EVA resulta em um aumento significativo na resistência ao 
impacto. $^{41}$ A Tabela 7 apresenta a denominação de cada blenda e suas respectivas composições.

Tabela 7 - Denominação das blendas e suas respectivas composições.

\begin{tabular}{lccccc}
\hline Amostra & $\begin{array}{c}\text { iPP } \\
(\%)\end{array}$ & $\begin{array}{c}\text { EVA65 } \\
(\%)\end{array}$ & $\begin{array}{c}\text { EVAOH } \\
(\%)\end{array}$ & $\begin{array}{c}\text { EVAm } \\
(\%)\end{array}$ & $\begin{array}{c}\text { Composição } \\
\%(\mathrm{~m} / \mathrm{m})\end{array}$ \\
\hline PP/EVA5 & 95 & 5 & - & - & $95 / 5$ \\
PP/EVA10 & 90 & 10 & - & - & $90 / 10$ \\
PP/EVAOH5 & 95 & - & 5 & - & $95 / 5$ \\
PP/EVAOH10 & 90 & - & 10 & - & $90 / 10$ \\
PP/EVAm5 & 95 & - & - & 5 & $95 / 5$ \\
PP/EVAm10 & 90 & - & - & 10 & $90 / 10$ \\
\hline
\end{tabular}

Fonte: Autoria própria.

A técnica de mistura por dissolução foi escolhida devido à impossibilidade do uso da técnica de mistura por extrusão. Inicialmente, foi realizado um teste de solubilidade em todos os polímeros.

\subsubsection{Teste de solubilidade dos polímeros para o preparo das blendas}

Para o preparo das blendas, o iPP e os diferentes copolímeros foram pulverizados em moinho criogênico marca IKA, modelo A 11, utilizando-se $\mathrm{N}_{2}$ líquido. As amostras foram inseridas no moinho juntamente com o $\mathrm{N}_{2}$ líquido e permaneceram em repouso por $10 \mathrm{~min}$, em seguida, foram moídas por $30 \mathrm{~s}$.

Os polímeros pulverizados foram transferidos para um balão de $50 \mathrm{~mL}$ acoplado a um sistema de refluxo. O sistema foi mantido sob agitação magnética sob aquecimento durante 12 h e, quando necessário, a solução foi aquecida à temperatura de ebulição de cada solvente utilizado. Posteriormente, os solventes foram evaporados em estufa a $80{ }^{\circ} \mathrm{C}$ sob pressão reduzidos durante $24 \mathrm{~h}$.

A Tabela 8 apresenta o resultado do teste de solubilidade de cada polímero testado em diferentes solventes: 
Tabela 8 - Solubilidade dos polímeros iPP, EVA65, EVAOH e EVAm em diferentes solventes.

\begin{tabular}{lcccc}
\hline Solventes & iPP & EVA65 & EVAOH & EVAm \\
\hline Dimetilformamida & insolúvel & solúvel & insolúvel & insolúvel \\
Dimetilsulfóxido & insolúvel & insolúvel & solúvel & insolúvel \\
Diclorometano & insolúvel & solúvel & insolúvel & insolúvel \\
Clorofórmio & insolúvel & solúvel & insolúvel & insolúvel \\
Tolueno & solúvel & solúvel & insolúvel* & insolúvel \\
\hline
\end{tabular}

* Apresentou alta interação com o solvente, com inchamento superior a $200 \%$.

Fonte: Autoria própria.

\subsubsection{Caracterização por Calorimetria Exploratória Diferencial}

A partir dos filmes preparados, o iPP puro e as blendas foram analisadas por Calorimetria Exploratória Diferencial (DSC). Os testes foram realizados no equipamento Elmer DSC 8000, situado no Departamento de Engenharia de Materiais da EESC-USP. As amostras foram pesadas em aproximadamente, $8 \mathrm{mg}$ em um porta amostras de alumínio, tendo como referência um porta amostra de mesmo material, porém vazio. Os experimentos foram realizados em uma taxa de aquecimento/resfriamento de $10^{\circ} \mathrm{C}$ por minuto, sob atmosfera de $\mathrm{N}_{2}$ com o fluxo em $20 \mathrm{~mL} \mathrm{~min}^{-1}$. A programação de temperatura para os ensaios do EVA65, EVAOH e EVAm estão apresentadas na Tabela 9, e as do iPP, juntamente com as blendas, estão na Tabela 10.

Tabela 9 - Programação da temperatura de ensaio de DSC para as amostras de EVA65, EVAOH e EVAm.

\begin{tabular}{lcc}
\hline Etapas & $\begin{array}{c}\text { Faixa de temperatura } \\
\left({ }^{\circ} \mathrm{C}\right)\end{array}$ & $\begin{array}{c}\text { Isoterma } \\
(\mathrm{min})\end{array}$ \\
\hline $1^{\mathrm{o}}$ aquecimento & $-70 \rightarrow 150$ & 2 \\
$1^{\circ}$ resfriamento & $150 \rightarrow-70$ & 2 \\
$2^{\mathrm{o}}$ aquecimento & $-70 \rightarrow 150$ & 2 \\
\hline
\end{tabular}

Fonte: Autoria própria. 
Tabela 10 - Programação da temperatura de ensaio de DSC para as amostras de iPP e todas as blendas.

\begin{tabular}{lcc}
\hline Etapas & $\begin{array}{c}\text { Faixa de temperatura } \\
\left({ }^{\circ} \mathrm{C}\right)\end{array}$ & $\begin{array}{c}\text { Isoterma } \\
(\mathrm{min})\end{array}$ \\
\hline $1^{\circ}$ aquecimento & $-70 \rightarrow 190$ & 2 \\
$1^{\circ}$ resfriamento & $190 \rightarrow-70$ & 2 \\
$2^{\circ}$ aquecimento & $-70 \rightarrow 190$ & 2 \\
\hline
\end{tabular}

Fonte: Autoria própria.

\subsubsection{Ensaios mecânicos por tração}

Os ensaios de tração foram realizados no equipamento Instron 5969 Universal Material Testing Machine, localizado no Departamento de Engenharia de Materiais da EESCUSP. Os corpos de prova foram prensados em uma prensa hidráulica a $190{ }^{\circ} \mathrm{C}$ por $60 \mathrm{~s}$ sem aplicação de pressão, 60 s com aplicação de 2 t de pressão e 60 s com 3,5 t. Em seguida, os filmes formados foram estampados em um molde com dimensões estabelecidas pela norma ASTM D-638, corpo de prova tipo IV.

Os corpos de prova tiveram sua espessura medida com um micrômetro e apresentaram a média de 0,16 mm. Estas amostras foram armazenadas em um dessecador com sílica seca por $24 \mathrm{~h}$ para posterior realização dos ensaios, sob temperatura ambiente e velocidade de extensão de $5 \mathrm{~mm} \mathrm{~min}^{-1}$. 


\section{RESULTADOS E DISCUSSÃO}

\subsection{Reações com o óleo de babaçu}

\subsubsection{Transesterificação dos triglicerídeos de babaçu}

Transesterificação é um termo usado para descrever uma classe de reações orgânicas onde um éster é transformado em outro através da troca do resíduo alcoxila. ${ }^{69,71}$ É uma reação semelhante à hidrólise, exceto pelo fato de que um álcool é empregado ao invés de água, podendo assim ser chamada também de alcoólise. ${ }^{68}$ Esta reação é reversível e acontece com a simples mistura dos reagentes, porém a presença de um catalisador acelera consideravelmente a reação, além de aumentar o rendimento. ${ }^{69}$

$\mathrm{Na}$ transesterificação de óleos vegetais, um triglicerídeo ou triacilglicerídeo, reage com um álcool na presença de uma base ou ácido fortes, produzindo ésteres de ácidos graxos e glicerol. Esta reação ocorre em três etapas e está representada na Figura 11.

Figura 11 - Etapas envolvidas na transesterificação de um triglicerídeo utilizando-se metanol.<smiles>[R1]C(=O)OCC(COC([R1])=O)OC(=O)[Y18][14CH3]</smiles><smiles>[R1]C(=O)OCC(O)COC([R1])=O</smiles>

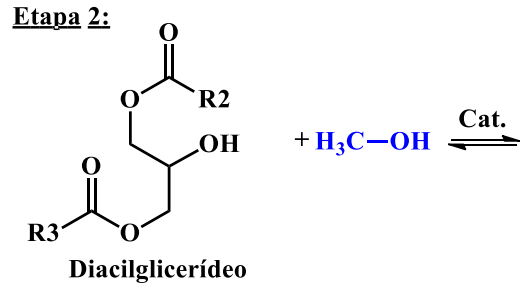<smiles>[R3]C(=O)OCC(O)CO</smiles>

Etapa 3:<smiles>[R3]C(=O)OCC(O)CO</smiles>

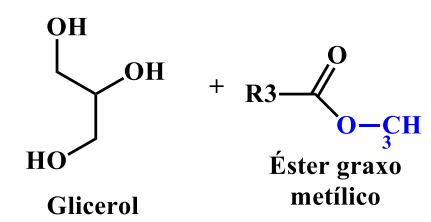

Fonte: Autoria própria.

A estequiometria da reação necessita da proporção molar de 3:1 de álcool por triglicerídeo, entretanto, devido ao caráter reversível da reação, o agente transesterificante é 
adicionado em excesso, sendo a proporção 6:1 amplamente utilizada na literatura, assim como neste trabalho. ${ }^{67-69}$

No que se refere ao agente esterificante, a reação de transesterificação ocorre na presença de catalisadores do tipo base de Brønsted, com a formação de alcóxidos. O sistema é mais eficaz quando se utiliza álcoois de baixa massa molar, por exemplo: metanol, etanol, propanol, butanol e álcool amílico, ${ }^{72}$ porém o metanol e o etanol são os mais utilizados devido seu baixo custo e por apresentarem melhores rendimentos, atribuídos ao seus menores impedimentos estéricos. ${ }^{68}$ Neste trabalho foi utilizado o metanol, devido à sua maior eficácia descrita na literatura, juntamente com o $\mathrm{KOH}$ para a formação do metóxido de potássio.

O mecanismo da transesterificação de triglicerídeos com metanol e $\mathrm{KOH}$ é apresentado na Figura 12. Inicialmente, é formada a espécie ativa, o metóxido, pela reação do metanol com a base $\mathrm{KOH}$ (I). Em seguida, as carbonilas dos triglicerídeos sofrem, uma a uma, ataques nucleofílicos dos metóxidos, formando intermediários tetraédricos. A partir do rearranjo destes intermediários com a regeneração da carbonila, são formados novos ésteres e um novo alcóxido (II), o qual, após a desprotonação do ácido conjugado da base, formado na reação (I), regenera a base de partida (III). Esse mecanismo ocorre sucessivamente, até os triglicerídeos sejam transformados em ésteres metílicos e glicerol.

Figura 12 - Mecanismo da transesterificação de um triglicerídeo utilizando-se metanol e KOH.
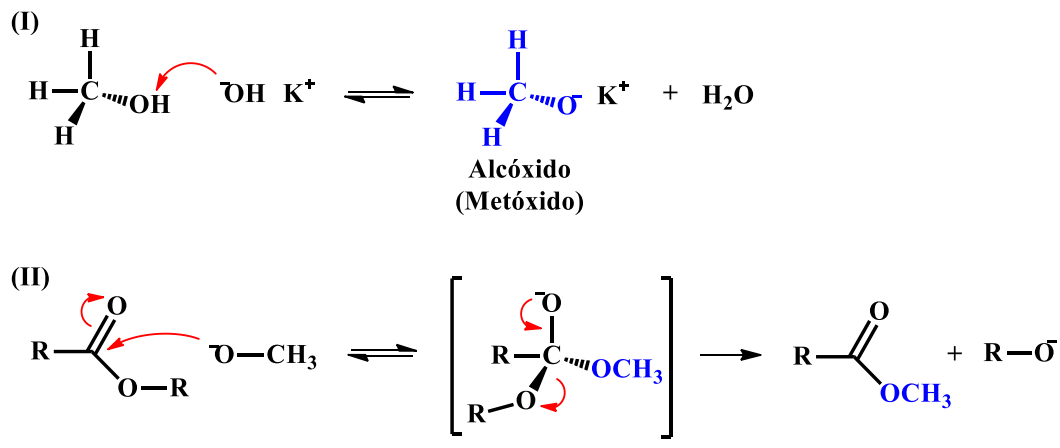

(III)

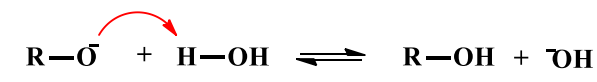

Fonte: Autoria própria.

Foram obtidos 17,50 gramas de ésteres metílicos partindo-se de 18,0 g de óleo de babaçu, o que representa um rendimento de $96,7 \%$. O restante para $100 \%$ pode estar relacionado a perdas durante a extração e ao valor, possivelmente, inexato da massa molecular média do óleo de babaçu e ésteres metílicos. 


\subsubsection{Hidrólise dos ésteres metílicos}

Como citado anteriormente, as reações de transesterificação e hidrólise são semelhantes, contudo, esta utiliza água ao invés de um álcool. A semelhança pode ser verificada no mecanismo da reação na Figura 13.

Figura 13 - Mecanismo da hidrólise de um éster metílico utilizando-se solução aquosa de $\mathrm{NaOH}$.

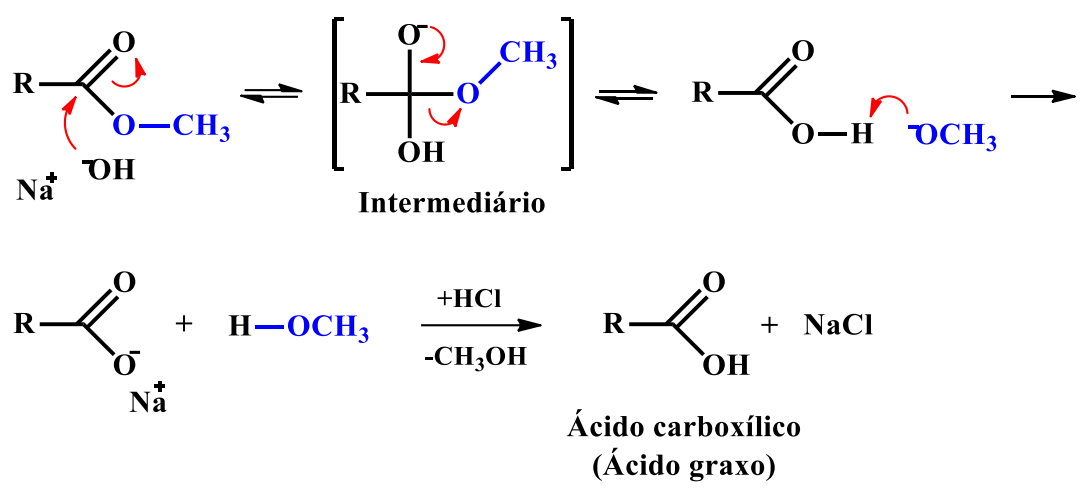

Fonte: Autoria própria.

Na hidrólise do éster metílico há a formação de sal orgânico, ou seja, a hidrólise é uma reação de saponificação dos ésteres metílicos e o produto corresponde ao sais de ácidos graxos. ${ }^{73}$ A acidificação do meio é necessária para neutralizar a base e, posteriormente, protonar o produto formado, convertendo-o ao correspondente ácido carboxílico.

A partir de 15,0 g de ésteres metílicos foram obtidos 11,93 g de ácidos carboxílicos, o que equivale a um rendimento de $84,3 \%$.

\subsubsection{Ativação do grupo acila - Síntese do cloreto de acila}

O ácido carboxílico, AGB, formado na hidrólise dos ésteres metílicos não é reativo o suficiente com as hidroxilas do EVAOH para a reação de esterificação. Dessa forma, foi necessário realizar uma modificação química onde a função ácido carboxílico é transformada em cloreto de acila (Figura 14). O método mais comumente utilizado é a reação do ácido carboxílico com os cloretos dos ácidos de fósforo ou de enxofre. ${ }^{74} \mathrm{O} \mathrm{SOCl}_{2}$ é amplamente utilizado $^{8,9,75}$ devido ao seu menor custo frente a outros reagentes e porque os subprodutos da reação são gases que podem ser facilmente separados da mistura reacional. ${ }^{74,76}$ 
Figura 14 - Mecanismo da formação do cloreto de lauroila a partir de um ácido carboxílico e cloreto de tionila, onde $\mathrm{R}$ representa uma cadeia hidrocarbônica de 11 carbonos.

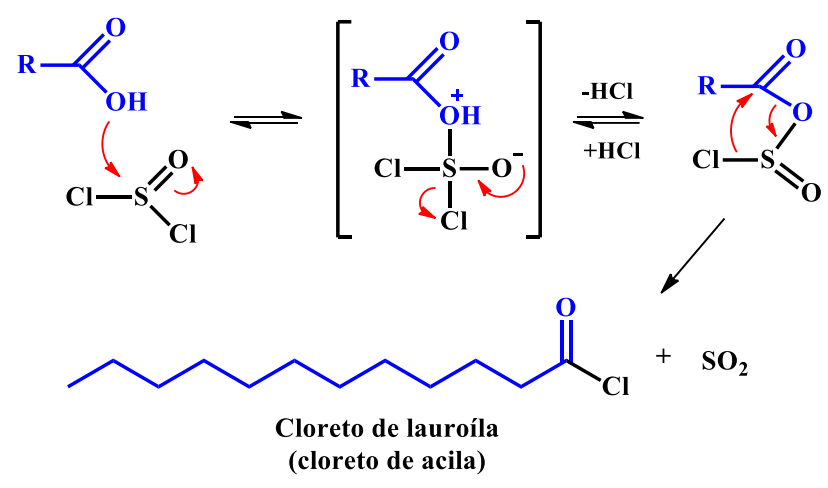

Fonte: Autoria própria.

\subsubsection{Caracterização do óleo de babaçu e seus produtos por $\mathrm{RMN}^{-1} \mathrm{H}$}

A técnica de $\mathrm{RMN}-{ }^{1} \mathrm{H}$ foi utilizada para caracterizar os triglicerídeos de babaçu assim como para mensurar o grau de conversão entre reagente e produto nas reações.

\subsubsection{Determinação da composição e da massa molar média}

Óleos vegetais podem ter suas composições graxas saturadas e insaturadas determinadas através da técnica de $\mathrm{RMN}-{ }^{1} \mathrm{H}$. Porém esta técnica permite diferenciar e quantificar apenas as cadeias graxas insaturadas, enquanto que para as cadeias saturadas, a quantificação é feita com base na somatória das cadeias saturadas, não permitindo distinção entre elas. ${ }^{77}$

A Figura 15 ilustra cadeias de ácidos graxos típicas em triglicerídeos ${ }^{77,78}$ e os caracteres em vermelho denotam os hidrogênios do espectro de $\mathrm{RMN}-{ }^{1} \mathrm{H}$ dos triglicerídeos de babaçu na Figura 16 com seus respectivos deslocamentos químicos. 
Figura 15 - Ilustração de cadeias de ácidos graxos típicas em triglicerídeos. Os caracteres em vermelho denotam os hidrogênios no espectro de RMN- ${ }^{1} \mathrm{H}$ da Figura 16.<smiles>[R]C(=O)OCC(COC([R])=O)OC([R])=O</smiles>

Triglicerídeo $\mathrm{R}=\mathrm{R}_{1}, \mathrm{R}_{2}, \mathrm{R}_{3}$ ou $\mathrm{R}_{4}$

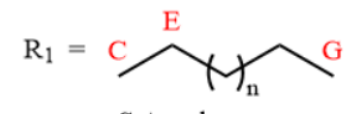

Saturado
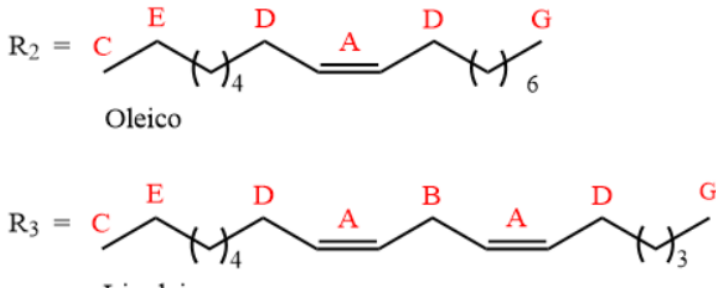

Linoleico

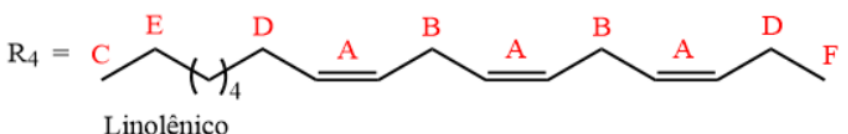

Linolênico

Fonte: Reproduzido da referência. ${ }^{78}$

Figura 16 - Espectro de $\mathrm{RMN}-{ }^{1} \mathrm{H}$ dos triglicerídeos de babaçu em $\mathrm{CDCl}_{3}$; picos atribuídos na Figura15.

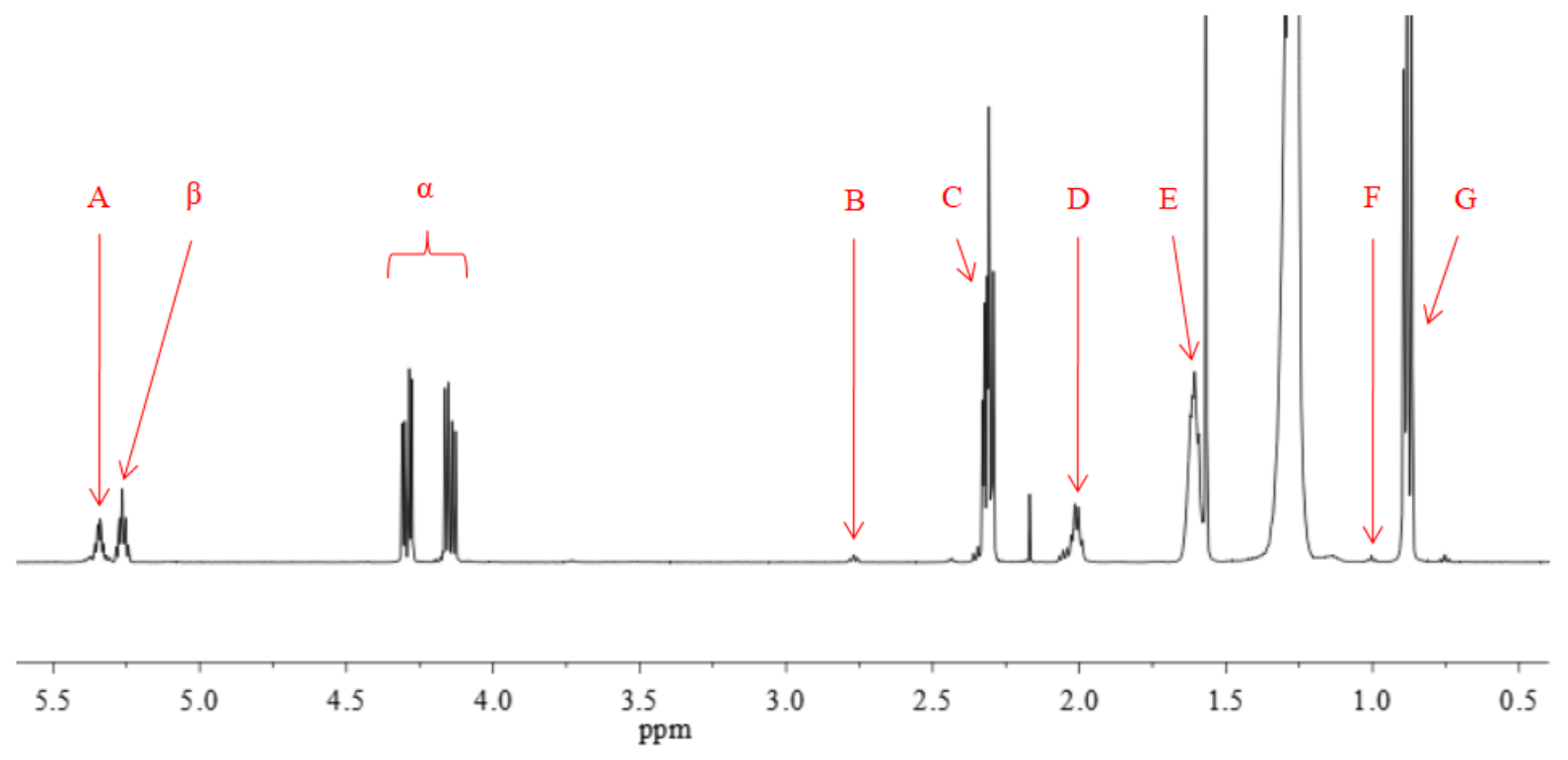

Fonte: Reproduzido da referência. ${ }^{78}$

Para a determinação da composição insaturada do óleo de babaçu, inicialmente, observou-se que os hidrogênios $\mathrm{F}$ referentes às metilas terminais do ácido linolênico não são detectados devido à presença mínima normalmente encontrada desse ácido graxo, conforme apresentado na literatura. ${ }^{62,67}$ A quantificação do ácido linoléico é feita com base no valor da integral do pico B em relação à integral do pico de referência $\mathrm{G}$. A integral do pico B confere a composição de $1,5 \%$ de ácido linoléico no óleo. O ácido oléico foi calculado de maneira 
análoga ao linoléico, porém utilizou-se a pico D para calcular a porcentagem de ácidos graxos insaturados. Subtraindo-se o valor de B, obteve-se o a composição de $11,5 \%$ do monoinsaturado ácido oléico. Dessa forma, a determinação da composição saturada foi feita pela simples subtração da composição insaturada, analogamente a subtração do valor da integral do pico D ao valor da integral do pico G. Os valores da composição graxa do óleo de babaçu estão representados na Tabela 11, juntamente com valores da literatura, afim de comparação.

Tabela 11 - Determinação da composição graxa do óleo de babaçu por RMN-1 H; valores experimentais e da literatura.

\begin{tabular}{lcc}
\hline Ácidos graxos & Experimental & Literatura \\
\hline Linolênico (18:2) & 1,5 & 0,9 \\
Oleico (18:1) & 11,5 & 6,5 \\
Saturados & 87,0 & 90,6 \\
\hline
\end{tabular}

Fonte: Autoria própria.

A determinação da massa molar do óleo exige também a diferenciação entre os compostos saturados, pois cada um deles tem sua respectiva massa molar. A técnica de cromatografia gasosa é frequentemente utilizada para separar esses compostos saturados, porém é necessária a utilização de soluções padrões de cada ácido graxo presente na amostra. No caso do óleo de babaçu são sete compostos saturados. Na literatura as composições não variam drasticamente e a discriminação dos compostos saturados não é essencial para este trabalho. Portanto, optou-se por calcular a massa molar média saturada do óleo de babaçu com base na literatura, conforme apresentado na Tabela 4, no subtópico 3.5.

A partir da composição dos ácidos graxos, a massa molar dos triglicerídeos foi calculada utilizando a média ponderada de seus componentes através da Equação 5,

$$
\begin{aligned}
M_{\text {trig }}=[ & \left(M M_{\text {caproico }} \cdot 0,033+M M_{\text {caprílico }} \cdot 0,092+M M_{\text {cáprico }} \cdot 0,096+\right. \\
& M M_{\text {láurico }} \cdot 0,547+M M_{\text {mirístico }} \cdot 0,118+M M_{\text {palmítico }} \cdot 0,048+ \\
& \left.\left.M_{\text {Mesteárico }} \cdot 0,021+M M_{\text {oléico }} \cdot 0,115+M M_{\text {linolênico }} \cdot 0,015\right) \cdot 3\right]+38
\end{aligned}
$$


onde $M_{\text {trig }}$ é o valor médio da massa molar dos triglicerídeos de babaçu, $M M$ são as massas molares de cada ácido graxo e os valores se referem às porcentagens obtidas por $\mathrm{RMN}-{ }^{1} \mathrm{H}$ para a composição insaturadas e às porcentagens saturadas baseadas na literatura. O resultado obtido para $M_{\text {trig }}$ foi de $733,7 \mathrm{~g} \mathrm{~mol}^{-1}$.

\subsubsection{Análise dos ésteres metílicos}

A reação de transesterificação dos triglicerídeos de babaçu separa o glicerol dos ácidos graxos formando um éster metílico. Desta forma, espera-se que no espectro de $\mathrm{RMN}-{ }^{1} \mathrm{H}$ do produto da reação na Figura 17 seja observado um sinal característico de uma metila esterificada na região de 3,67 ppm e, devido à separação e purificação da fase orgânica da redução, não sejam mais observados os sinais referentes ao glicerol.

$\mathrm{O}$ sinal $\mathrm{G}$ da metila em $0,88 \mathrm{ppm}$ dos triglicerídeos de babaçu permanece com o ambiente químico inalterado. Portanto ele foi utilizado como padrão interno para comparação entre os espectros. $\mathrm{O}$ pico $\mathrm{C}$ em 2,30 ppm manteve exatamente a mesma proporção, pois se trata de hidrogênios que também mantiveram o mesmo ambiente químico. Para o pico referente à metila esterificada em 3,67 ppm obteve-se o valor da integral de 2,92, o que representa uma taxa de conversão da reação de triglicerídeos para ésteres metílicos de 97,3 \%. O desaparecimento completo dos picos dos hidrogênios do glicerol indica uma taxa de conversão de aproximadamente $100 \%$.

Figura 17 - Espectro de RMN- ${ }^{-1} \mathrm{H}$ dos ésteres metílicos de babaçu em $\mathrm{CDCl}_{3}$.

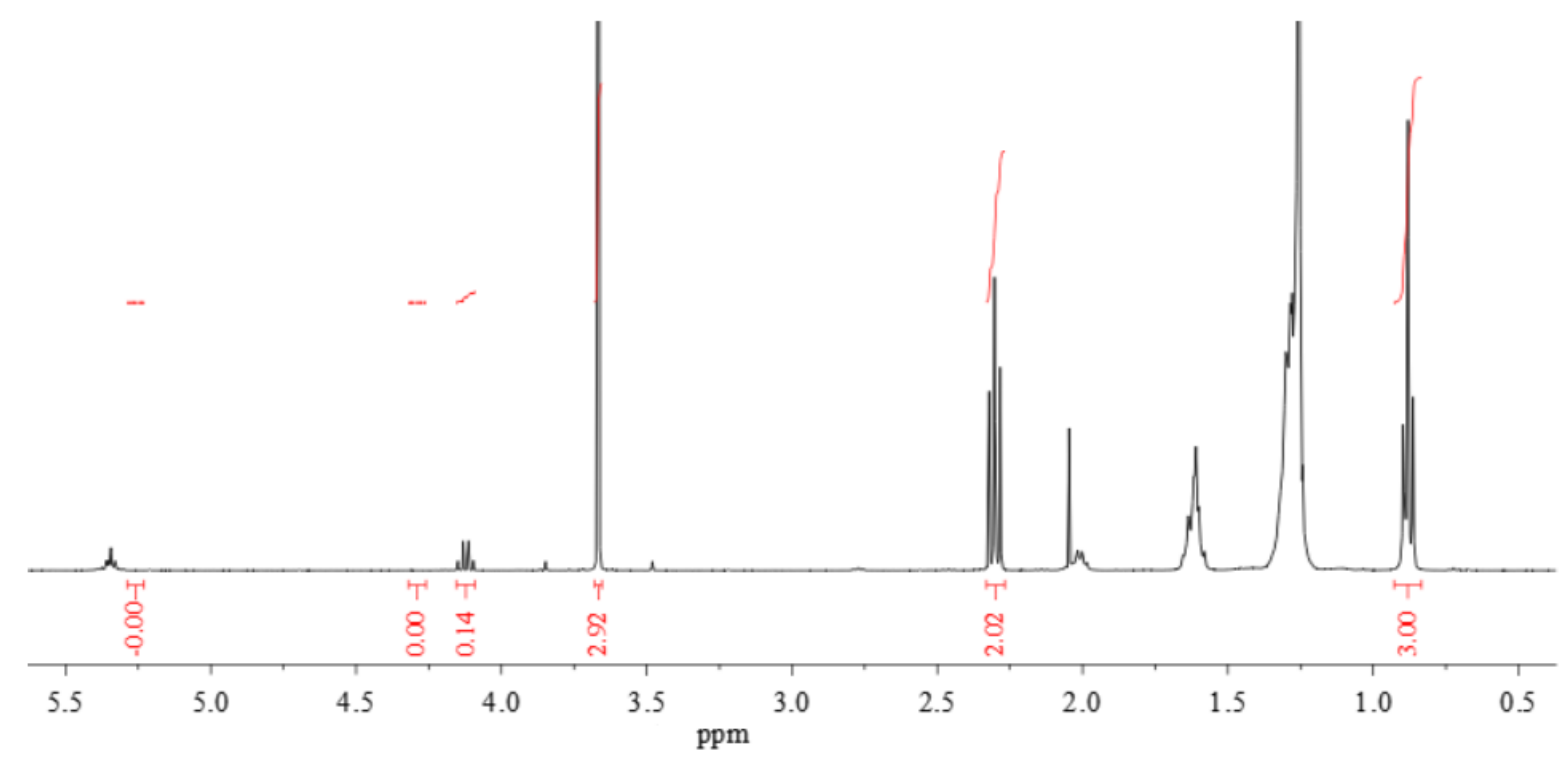

Fonte: Autoria própria. 


\subsubsection{Análise dos ácidos carboxílicos}

A hidrólise dos ésteres metílicos produz ácidos carboxílicos, desta maneira espera-se que o pico das metilas esterificadas em 3,67 ppm desapareça no espectro a seguir (Figura 18):

Figura 18 - Espectro de RMN- ${ }^{1} \mathrm{H}$ dos ésteres metílicos de babaçu em $\mathrm{CDCl}_{3}$.

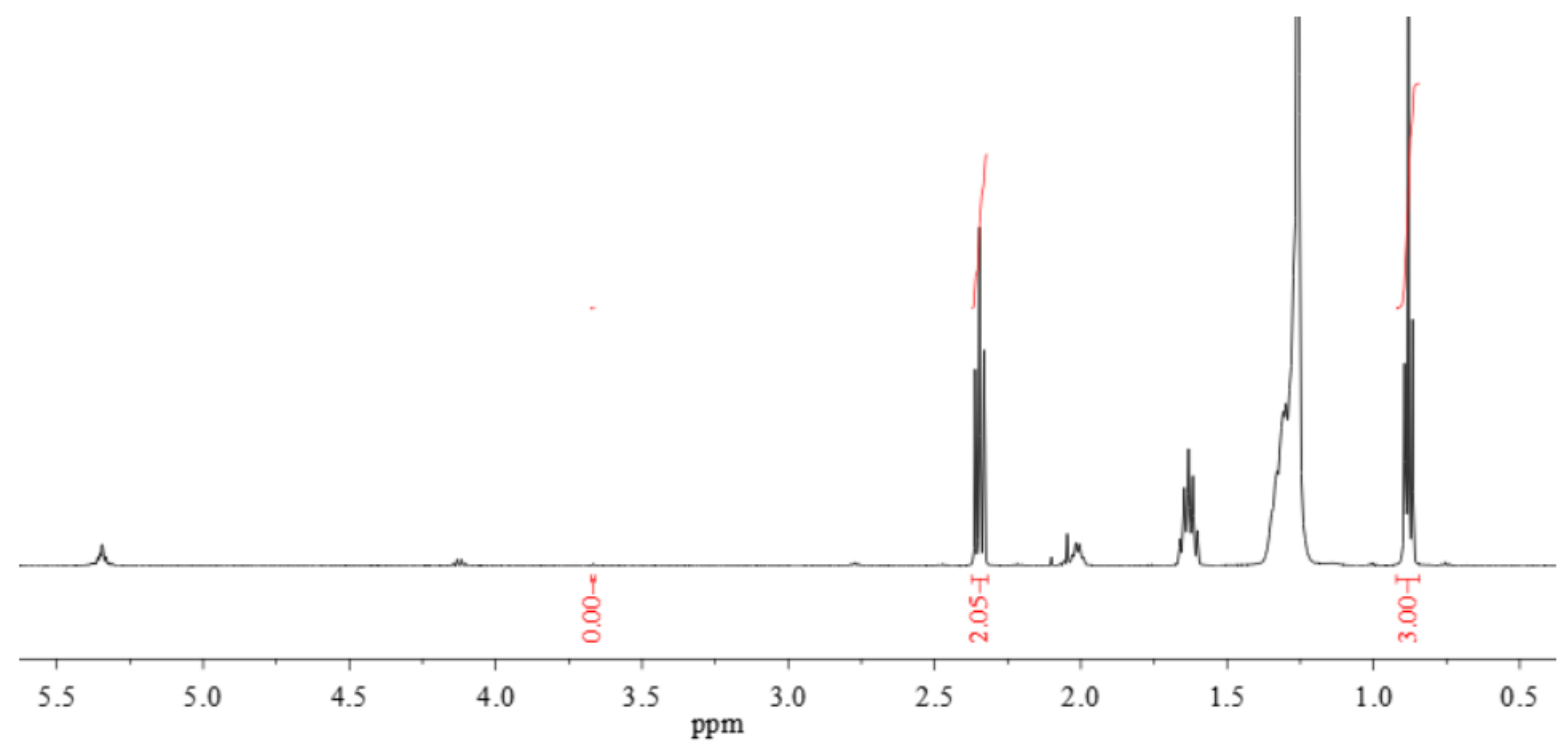

Fonte: Autoria própria.

Novamente o sinal G em 0,88 ppm foi mantido para comparação. O sinal C em 2,30 ppm manteve a relação de hidrogênios devido a conservação do ambiente químico e o sinal da metila esterificada em 3,67 ppm apresentou integral com valor zero, indicando uma taxa de conversão de ésteres metílicos para ácidos carboxílicos de $100 \%$, aproximadamente.

A Tabela 12 apresenta a quantidade de reagente utilizado para as reações de transesterificação e hidrólise do óleo de babaçu, a quantidade de produto obtido e os rendimentos mássicos e a taxa de conversão dos produtos das reações.

Tabela 12 - Quantidade de reagente, produtos, rendimentos mássicos e taxas de conversão das reações de transesterificação e hidrólise do óleo de babaçu.

\begin{tabular}{lcccc}
\hline Reação & $\begin{array}{c}\text { Reagente } \\
(\mathrm{g})\end{array}$ & $\begin{array}{c}\text { Produto } \\
(\mathrm{g})\end{array}$ & $\begin{array}{c}\text { Rendimento } \\
\text { mássico }(\%)\end{array}$ & $\begin{array}{c}\text { Taxa de } \\
\text { conversão }(\%)\end{array}$ \\
\hline Transesterificação & 18,0 & 17,5 & 96,7 & 97,3 \\
Hidrólise & 15,0 & 11,9 & $84,3^{\mathrm{a}}$ & 100,0 \\
\hline
\end{tabular}

${ }^{\text {a }}$ Houve perda de massa considerável durante a purificação do ácido carboxílico.

Fonte: Autoria própria. 


\subsection{Reações com o copolímero EVA65}

\subsubsection{Hidrólise do EVA65 - Esterificação do EVAOH}

O mecanismo da reação da retro-titulação está representado na Figura 19. A reação envolve o ataque nucleofílico da piridina à carbonila do anidrido formando um intermediário que, ao se rearranjar, cria um ânion acetato e um derivado de piridina (solvólise) ${ }^{79}$ Este derivado reage prontamente com a hidroxila disponível no EVAOH. Ao final da reação há a formação de um éster (o EVA de partida), um ácido carboxílico e a piridina regenerada. Este derivado reage prontamente com a hidroxila disponível no EVA hidrolisado. Ao final da reação há a formação de um éster (o EVA de partida), um ácido carboxílico e a piridina regenerada.

Figura 19 - Mecanismo da reação de retro-titulação. Posteriormente, o anidrido em excesso é titulado.

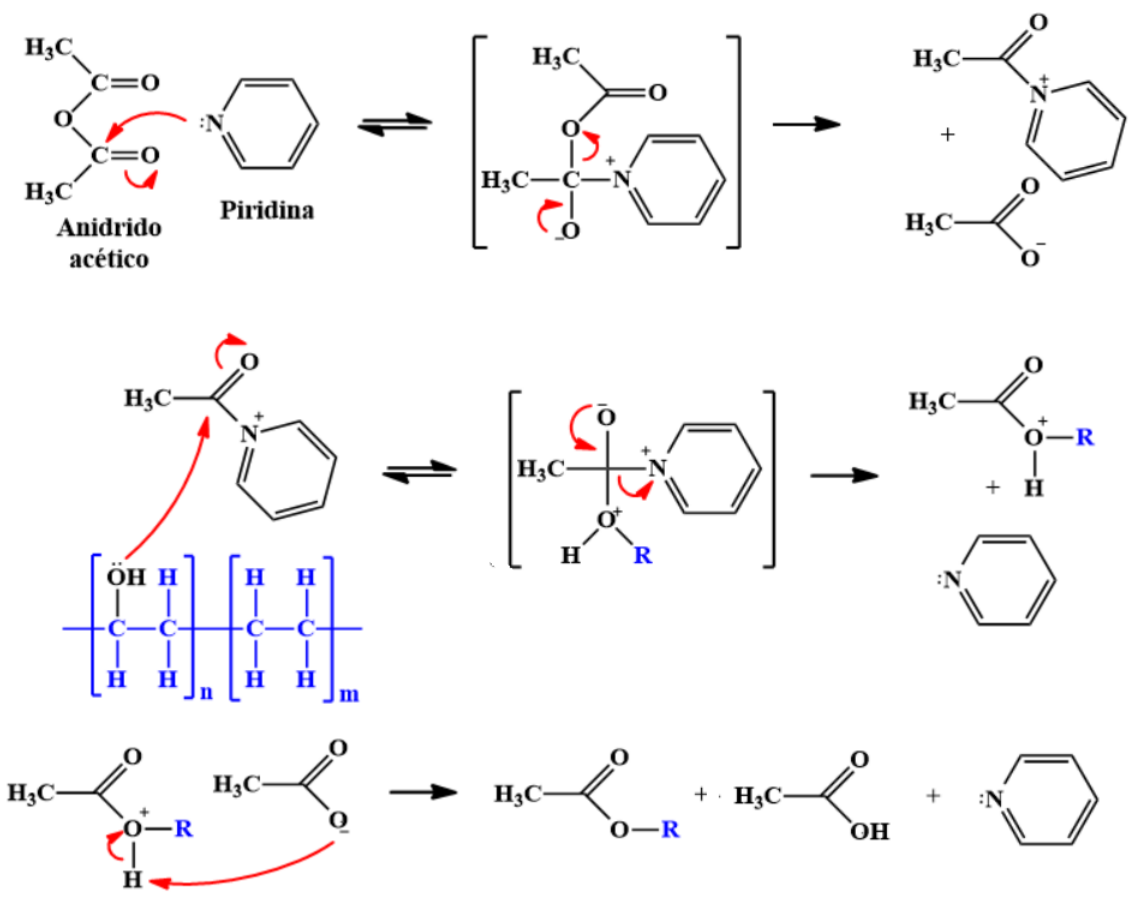

Fonte: Autoria própria 


\subsubsection{Esterificação do EVAOH - Síntese do EVAm}

A reação de esterificação do EVA65 se torna possível porque, após sua hidrólise,o produto formado, EVAOH, possui grupos hidroxila que são agentes nucleófilos eficientes, diferentemente dos grupos acetato de vinila, frente à reação com o cloreto de ácido. ${ }^{8,9} \mathrm{~A}$ reação está representada na Figura 20.

Figura 20 - Reação de esterificação do EVA hidrolisado com cloreto de ácido.

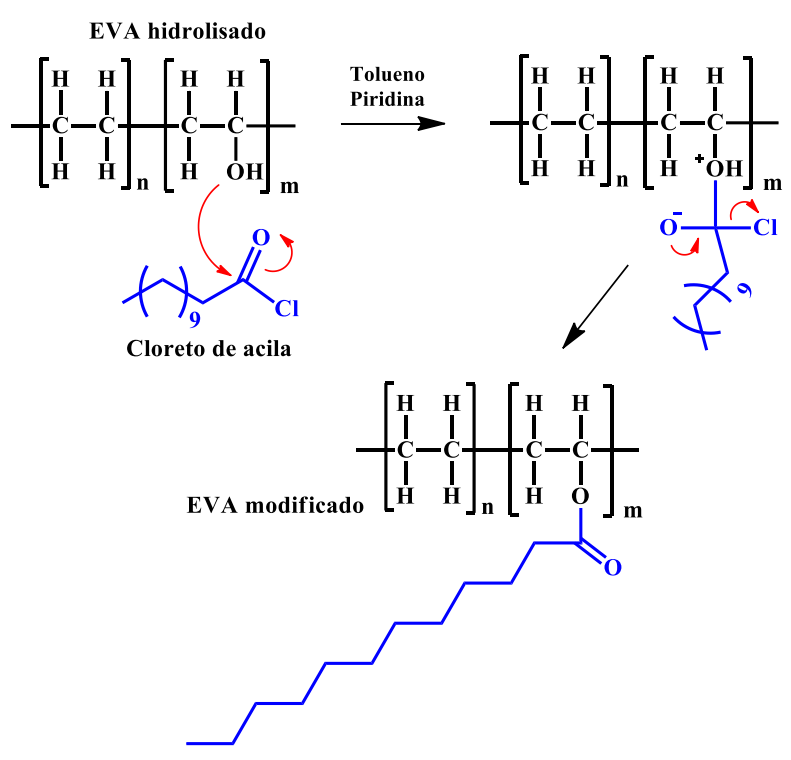

Fonte: Autoria própria.

\subsubsection{Caracterização do EVA65, EVAOH e EVAm por FTIR}

O EVA65, EVAOH, EVAm e os AGB foram caracterizados por espectroscopia FTIR, conforme apresentado na Figura 21. 
Figura 21 - Espectros FTIR do EVA65, EVAOH, AGB e EVAm.

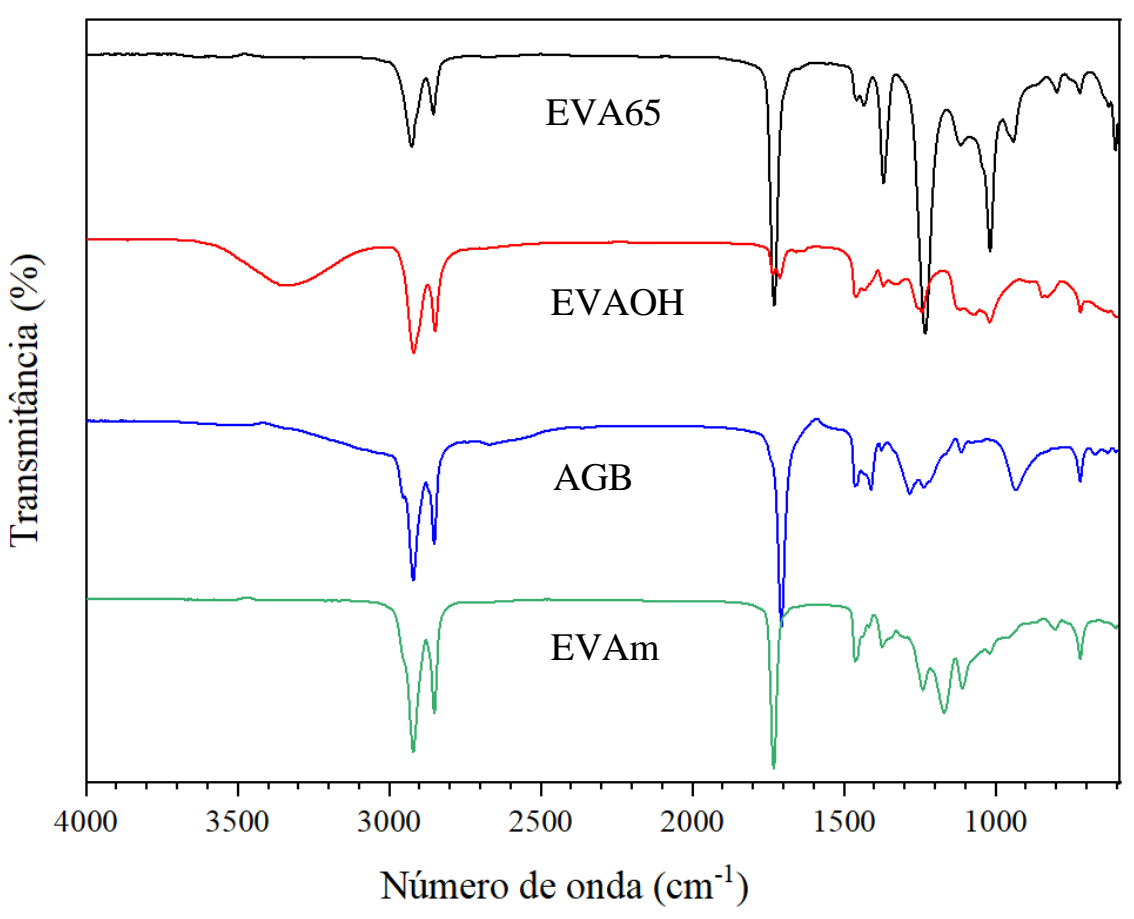

Fonte: Autoria própria.

Como esperado e já relatado na literatura ${ }^{40,80}$ a intensidade da banda de absorção relativa à carbonila do grupo éster do acetato de vinila, em $1.735 \mathrm{~cm}^{-1}$, diminuiu e, após a reação de hidrólise, uma banda de absorção alargada referente aos grupos -OH surge no intervalo de $3.200-3.400 \mathrm{~cm}^{-1}$.

O teor de hidrólise do EVA65 foi determinado por retro-titulação descrito nos métodos desse trabalho, no item 4.4.3. O teor de hidrólise do EVA65 é a porcentagem de grupos acetato de vinila transformados em grupos -OH. O valor alcançado foi de 83,7 \% de hidrólise. O não desaparecimento da banda referente ao acetato de vinila indica que a hidrólise não foi total e o valor obtido na hidrólise corrobora com esta observação.

Para a reação de esterificação dos ácidos graxos de babaçu no EVAOH, esperava-se que houvesse a diminuição da banda referente aos grupos -OH e o aumento da banda já mencionada do acetato de vinila. Ou seja, esperava-se a regeneração do perfil de um éster, o mesmo observado no EVA65. O espectro dos ácidos graxos de babaçu foi também inserido na Figura 19.

Os valores do número de onda para cada função orgânica analisada nesta discussão estão representados na Tabela 13. 
Tabela 13 - Valores de absorção no espectro de infravermelho para algumas funções orgânicas.

\begin{tabular}{|c|c|c|}
\hline $\begin{array}{l}\text { Número de onda } \\
\left(\mathrm{cm}^{-1}\right)\end{array}$ & Grupo Funcional & Comentários \\
\hline $3.640-3.610$ & $\begin{array}{l}\mathrm{O}-\mathrm{H} \\
\text { livre }\end{array}$ & Banda estreita \\
\hline $3.600-3.200$ & $\begin{array}{c}\mathrm{O}-\mathrm{H} \\
\text { associado }\end{array}$ & $\begin{array}{c}3.400 \text { - 3.200: Banda alargada, resultante de } \\
\text { associação polimérica }\end{array}$ \\
\hline $2.960-2.850$ & $\begin{array}{l}\mathrm{C}-\mathrm{H} \\
\text { alifáticos }\end{array}$ & $\begin{array}{l}2960 \text { - 2.850: Carbono primário e secundário } \\
\text { 2.890 - 2880: Carbono terciário }\end{array}$ \\
\hline $1.760-1.710$ & $\begin{array}{l}\mathrm{C}=\mathrm{O} \\
\text { ác. carboxílico }\end{array}$ & Banda estreita \\
\hline $1.750-1740$ & $\begin{array}{l}\mathrm{C}=\mathrm{O} \\
\text { ác. éster }\end{array}$ & Banda estreita \\
\hline $1.420-1200$ & $\begin{array}{l}\mathrm{C}-\mathrm{O} \\
\text { ác. carboxílico }\end{array}$ & $\begin{array}{l}\text { Duas bandas de formação axial: Referente ao C-O e à } \\
\text { deformação angular no plano da ligação O-H }\end{array}$ \\
\hline $1.300-1050$ & $\begin{array}{l}\mathrm{C}-\mathrm{O} \\
\text { ác. éster }\end{array}$ & $\begin{array}{l}1.300 \text { - 1.050: Ésteres alifáticos } \\
1.200-1.050: \text { Ésteres insaturados }\end{array}$ \\
\hline
\end{tabular}

Fonte: Reproduzido da referência. ${ }^{81}$

\subsubsection{Caracterização do EVA65, EVAOH e EVAm por TGA}

As análises termogravimétricas foram realizadas para investigar a estabilidade térmica do EVA65 e dos polímeros sintetizados EVAOH e EVAm. Esta análise oferece informações sobre a decomposição dos materiais, que são importantes para outros possíveis processos, por exemplo, verificar as condições mais adequadas de processamento, ou também, os limites de temperatura para a análise de Calorimetria Exploratória Diferencial, evitando a decomposição do analito e, por consequência, a volatilização de substâncias tóxicas ou corrosivas, que podem danificar o equipamento. ${ }^{82}$

A Figura 22 apresenta as curvas das análises termogravimétricas (TGA) e suas respectivas curvas derivadas (DTG) para os polímeros EVA65, EVAOH e EVAm. 
Figura 22 - Curvas (a) TGA e (b) DTG dos copolímeros EVA65, EVAOH e EVAm.
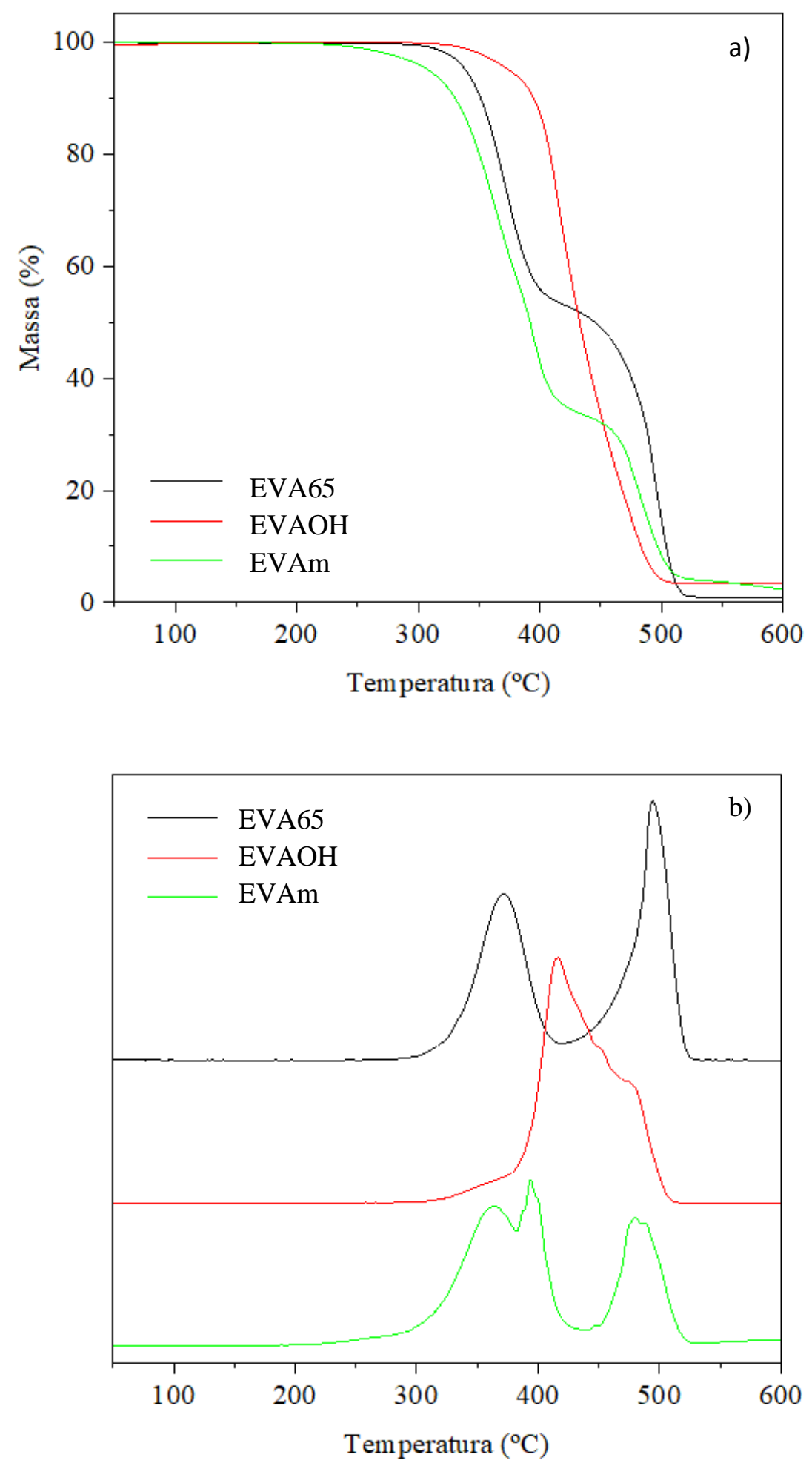

Fonte: Autoria própria.

Tanto na curva TGA, Figura 22 (a), quanto na curva DTG, Figura 20 (b), fica evidente que a decomposição térmica do EVA 65 ocorre em duas etapas. A primeira, com temperatura de início de decomposição ( $\left.\mathrm{T}_{\text {onset }}\right)$ em torno de $270{ }^{\circ} \mathrm{C}$ e temperatura de taxa máxima de perda 
de massa $\left(\mathrm{T}_{\mathrm{p}}\right)$ de $372{ }^{\circ} \mathrm{C}$, está relacionada à perda de massa pela formação de ácido acético em decorrência da decomposição do grupo acetato de etila. A segunda, $\mathrm{T}_{\text {onset }} 430{ }^{\circ} \mathrm{C}$, é a decomposição do etileno parcialmente insaturado remanescente. Na literatura é relatado que, na primeira etapa, os gases evoluídos consistem em ácido acético, dióxido de carbono e água, seguidos de produtos como 1-buteno, dióxido de carbono, etileno, metano e monóxido de carbono e outros hidrocarbonetos variando de $\mathrm{C} 8$ a C26. ${ }^{83,84}$

A retro-titulação do EVAOH mostrou uma taxa de conversão de 83,7 \% dos grupos acetato de vinila para álcool vinílico, ou seja, o principal componente do copolímero EVAOH etileno e o é álcool vinílico. O EVAOH obtido na hidrólise do EVA65 equivale a, aproximadamente, um EVAOH com $32 \%$ (mol) de álcool vinílico. A curva DTG do EVAOH mostra também mais de uma etapa envolvida na decomposição. Com base na literatura, um EVAOH com $32 \%$ (mol) de etileno, a uma taxa de aquecimento constante de $10{ }^{\circ} \mathrm{C} \mathrm{min}^{-1}$, apresenta duas etapas de decomposição. A primeira corresponde à degradação do álcool vinílico, com $\mathrm{T}_{\mathrm{p}}$ de $390{ }^{\circ} \mathrm{C}$, a segunda, decorre da decomposição o etileno remanescente em $\mathrm{T}_{\mathrm{p}} 480{ }^{\circ} \mathrm{C}$. Os valores obtidos na análise do EVAOH são próximos, com $372{ }^{\circ} \mathrm{C}$ para a primeira etapa e $494^{\circ} \mathrm{C}$ para a segunda. Inesperadamente, foi observada uma terceira variação de perda de massa para o EVAOH analisado, em $450^{\circ} \mathrm{C}$. Tal variação pode ser atribuída ao fato de que, na prática, o material é um terpolímero, com acetato de vinila não hidrolisado presente na sua composição e, a decomposição térmica de uma nova função orgânica pode afetar o comportamento térmico das outras. Sobre os a gases volatilizados durante a decomposição térmica, abaixo de $300{ }^{\circ} \mathrm{C}$, o principal produto é a água, acima dessa temperatura, é relatado a emissão de aldeídos e cetonas saturados e insaturados. ${ }^{50,85,86}$

A curva TGA do EVAm mostra que para a temperatura de $400{ }^{\circ} \mathrm{C}$, que envolve a primeira etapa de decomposição, houve uma perda de massa de $65 \%$, enquanto que para o EVA65, a perda foi de $44 \%$. Esta observação pode ser atribuída ao fato que para o EVA65 da ligação éster do copolímero gera o produto ácido acético de massa molar $60,0 \mathrm{~g} \mathrm{~mol}^{-1}$, enquanto que para o EVAm os produtos formados são ácidos carboxílicos de cadeia maior, por exemplo, o ácido láurico, de massa molar 200,3 $\mathrm{g} \mathrm{mol}^{-1}$, o que corrobora com a síntese de um novo éster a partir da esterificação entre EVAOH e os ácidos graxos de babaçu. A curva DTG do EVAm apresenta uma característica relatada na literatura que é a variação da massa ocorrer a temperatura de, aproximadamente, $200^{\circ} \mathrm{C}$, um valor bastante inferior ao observado no EVA65 $\left(280^{\circ} \mathrm{C}\right)$. Dados da literatura sugerem que os grupos -OH remanescentes da esterificação possuem um efeito catalítico na decomposição do éster, ${ }^{83}$ seja o acetato de etila ou os ésteres de cadeia extensa do EVAm. A curva DTG do EVAm, apresenta um pico estreito 
em $395{ }^{\circ} \mathrm{C}$, que pode ser atribuído a essas hidroxilas remanescentes e, de maneira geral, a curva DTG mostra a regeneração do perfil característico do copolímero com a função éster, o que também corrobora com a esterificação entre o EVA65 e o ácido graxo.

As temperaturas que correspondem ao início da decomposição, $\mathrm{T}_{\text {onset }}$ e as correspondentes à máxima taxa de perda de massa, $\mathrm{T}_{\mathrm{p}}$, obtidas pelo valor do pico da curva DTG, estão apresentadas na Tabela 14. A $\mathrm{T}_{\text {onset }}$ foi apresentada apenas para as primeiras etapas de decomposição.

Tabela 14 - $\mathrm{T}_{\text {onset }}$ da primeira etapa de degradação e $\mathrm{T}_{\mathrm{p}}$ de todas as etapas de degradação observadas.

\begin{tabular}{lcc}
\hline Amostras & $\begin{array}{c}\mathrm{T}_{\text {onset }} \\
\left({ }^{\circ} \mathrm{C}\right)\end{array}$ & $\begin{array}{c}\mathrm{T}_{\mathrm{p}} \\
\left({ }^{\circ} \mathrm{C}\right)\end{array}$ \\
\hline EVA65 & 270 & $372 ; 494$ \\
EVAOH & 290 & $416 ; 473$ \\
EVAm & 210 & $363 ; 394 ; 480$ \\
\hline
\end{tabular}

Fonte: Autoria própria.

\subsubsection{Materiais obtidos}

A Figura 23 apresenta o EVA65 de partida e os materiais obtidos a partir dele, o EVAOH e EVAm.

Figura 23 - Imagens obtidas do EVA65, EVAOH e EVAm.
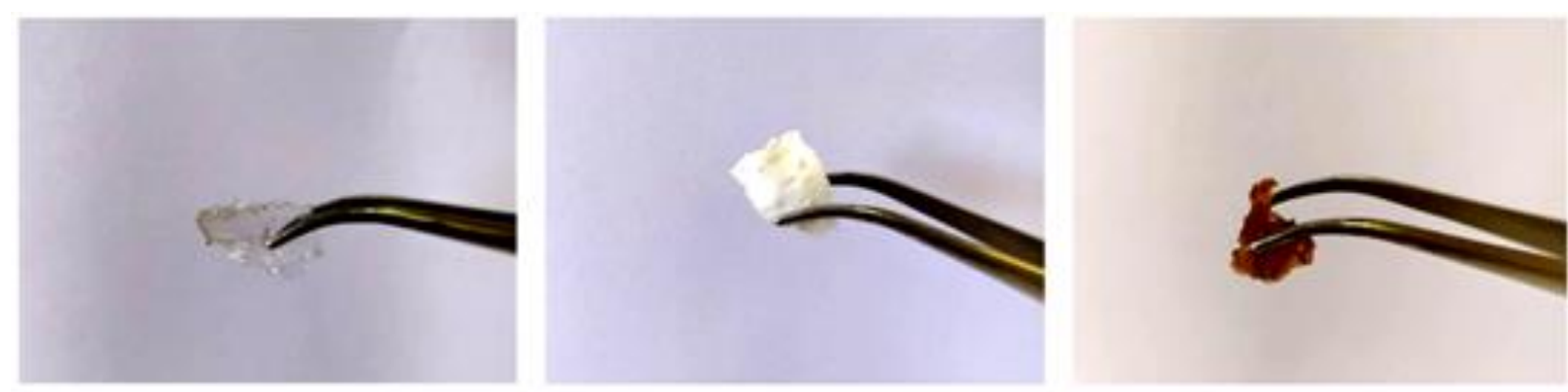

Fonte: Autoria própria.

O EVA65 apresentou-se transparente e bastante flexível; o EVAOH apresentou a cor branca, maior rigidez e menor densidade, em comparação ao EVA65. Após ser fundido, o EVAOH também adquiriu transparência; o EVAm apresentou a coloração castanho escuro, pouco translúcido e ainda mais flexível que o EVA65. 


\subsection{Blendas}

\subsubsection{Caracterizações dos polímeros puros e das blendas por DSC}

As análises DSC tiveram como objetivo investigar as transições térmicas $T_{g}$ e $T_{m}$, assim como cristalinidade dos materiais puros e das blendas. As curvas do segundo aquecimento dos copolímeros EVA65, EVAOH e EVAm estão representadas na Figura 24 a) e b).

Para o EVA65, foi observada uma variação na linha base em $19,9^{\circ} \mathrm{C}$, relativa à $\mathrm{T}_{\mathrm{g}}$. Nenhum outro evento térmico foi observado para esta curva. Para o EVAOH foi observada $T_{g}$ na temperatura de $54,8^{\circ} \mathrm{C}$ (Tabela 15). Ambos valores estão bastante próximos do observado na literatura. ${ }^{32,87}$ Esse deslocamento para temperaturas superiores se deve ao fato de que na hidrólise do EVA65, os grupos acetato de vinila são lugar aos grupos hidroxila.

Tabela 15 - Temperaturas de transição vítrea observadas nas curvas DSC dos EVAs.

\begin{tabular}{lc}
\hline Amostras & $\mathrm{T}_{\mathrm{g}}$ \\
& $\left({ }^{\circ} \mathrm{C}\right)$ \\
\hline EVA65 & $-19,9$ \\
EVAOH & 54,8 \\
EVAm & - \\
\hline
\end{tabular}

Fonte: Autoria própria.

Visto que a hidrólise alcançou altos valores, a maioria dos grupos acetato de vinila foram substituídos. Os novos grupos hidroxila têm interações intermoleculares fortes entre si, do tipo ligação de hidrogênio. Essas interações favorecem a cristalização e, consequentemente, a elevação das temperaturas tanto da $T_{g}$, como também da $T_{m}$. Também foram observados dois eventos de fusão, um a $-10,8{ }^{\circ} \mathrm{C}$ e outro a $113,8{ }^{\circ} \mathrm{C}$, referentes ao EVAm e EVAOH, respectivamente. Estes eventos térmicos foram inesperados, Estes eventos podem ser atribuídos às fusões de compostos de baixa massa molar, que fundem a menores temperaturas, visto que o EVAOH funde a temperaturas superiores ao intervalo investigado e o EVAm se apresentou reticulado. 
Figura 24 - a) Curvas DSC do segundo aquecimento dos copolímeros EVA65, EVAOH e EVAm; b) aproximação em uma menor faixa de temperatura.
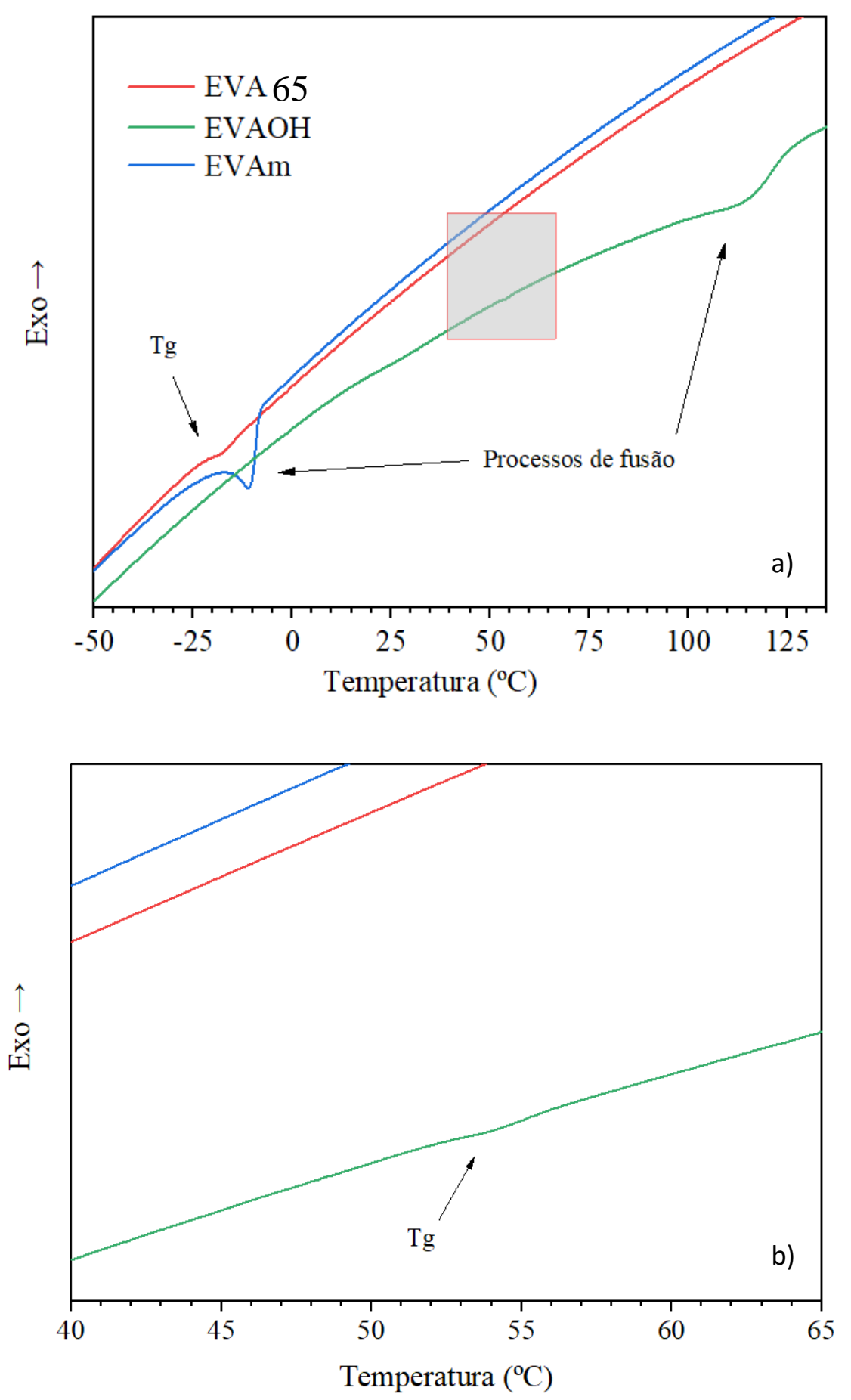

Fonte: Autoria própria.

As curvas DSC do segundo aquecimento do iPP e de todas as blendas produzidas estão apresentadas na Figura 25 a) e b). Os picos de fusão observados na Figura 25 a) se concentraram na mesma faixa de temperatura, em torno da $\mathrm{T}_{\mathrm{m}}$ do iPP em $165,7{ }^{\circ} \mathrm{C}$ com 
variação menor que $\pm 1{ }^{\circ} \mathrm{C}$, com exceção da blenda PP/EVAm10, cujo pico de $\mathrm{T}_{\mathrm{m}}$ foi deslocado para a $156,4^{\circ} \mathrm{C}$.

Figura 25 - a) Curvas DSC do segundo aquecimento do iPP e de todas as blendas; b) aproximação em uma menor faixa de temperatura.
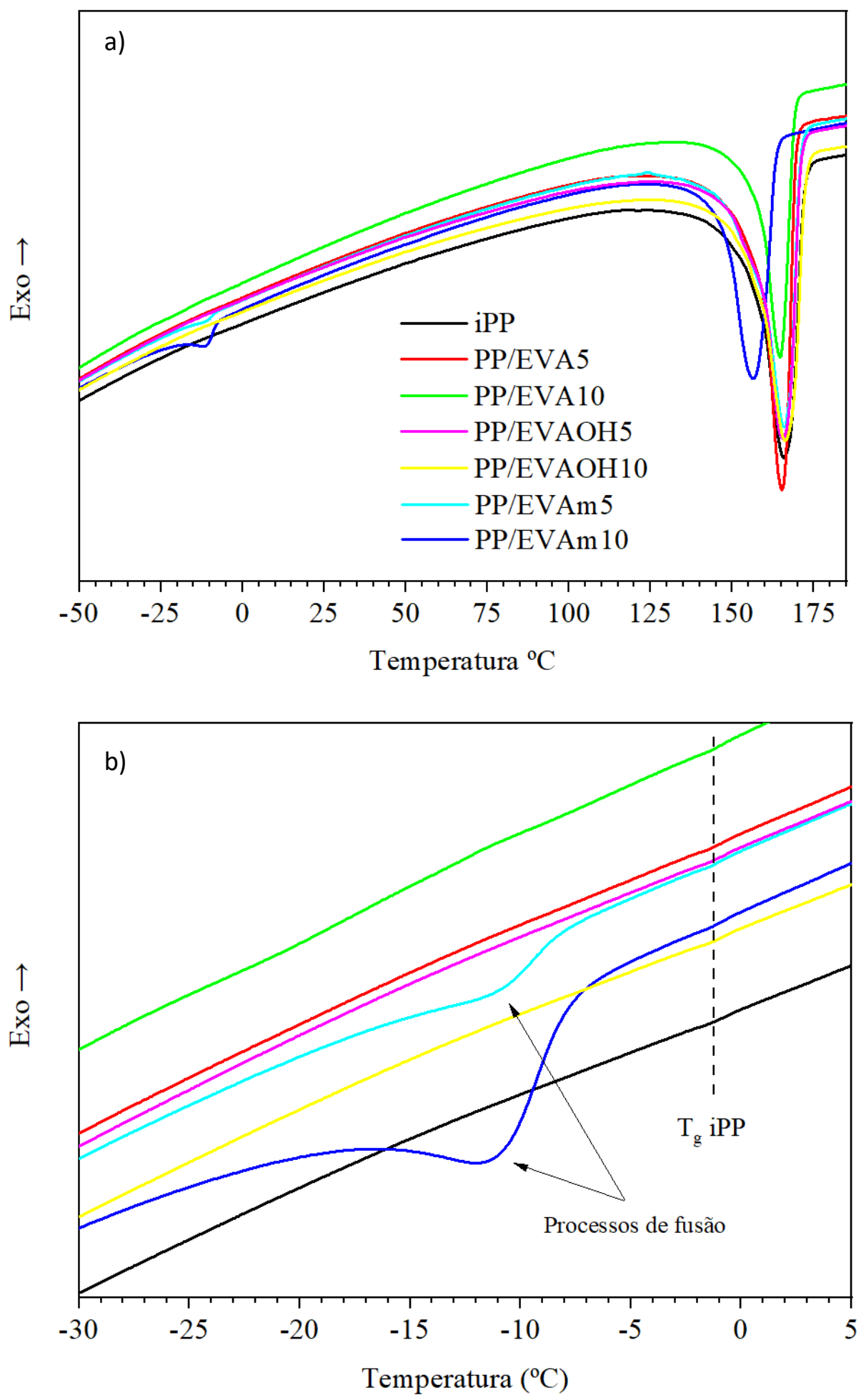

Fonte: Autoria própria. 
Esse tipo deslocamento acontece quando os componentes da blenda são parcialmente miscíveis entre si, porém este comportamento não se manifestou na blenda PP/EVAm5. Isso indica que a diferença de 5 para $10 \%(\mathrm{~m} / \mathrm{m})$ de EVAm na blenda com iPP pode ter modificado a estrutura da blenda, melhorado a compatibilidade na blenda de maior concentração de EVAm. Porém, esta compatibilidade não é esperada, já que o EVAm se apresentou insolúvel no melhor solvente escolhido para a dissolução e, na blenda, ficou disperso na matriz iPP em pequenas partículas visíveis a olho nu. Outro fato que corrobora com a imiscibilidade das blendas iPP/EVA foi a não alteração da $\mathrm{T}_{\mathrm{g}}$ do iPP puro e de todas as suas blendas, observada em torno de $-1,4{ }^{\circ} \mathrm{C}$, destacada na Figura 25 b). Nesta ilustração também pode ser observado os processos de fusão das blendas iPP/EVAm, na mesma faixa de temperatura verificada na curva DSC do EVAm puro. Estes eventos de fusão, atribuídos à hipótese de fusão de compostos de baixa massa molar derivados do EVAm, persistiram nas concentrações inferiores de EVAm presentes nas blendas.

A Tabela 16 dados obtidos a partir do segundo aquecimento do iPP e de todas as suas blendas.

Tabela 16 - Dados do segundo obtidos das curvas do segundo aquecimento para o iPP e suas blendas.

\begin{tabular}{lcc}
\hline Amostras & $\begin{array}{c}\mathrm{T}_{\mathrm{m}} \\
\left({ }^{\circ} \mathrm{C}\right)\end{array}$ & $\begin{array}{c}\Delta H_{f} \\
(\mathrm{~J} / \mathrm{g})\end{array}$ \\
\hline iPP & 165,7 & 85,5 \\
PP/EVA5 & 165,2 & 84,2 \\
PP/EVA10 & 164,7 & 52,8 \\
PP/EVAOH5 & 165,5 & 78,5 \\
PP/EVAOH10 & 166,3 & 82,2 \\
PP/EVAm5 & 166,0 & 83,5 \\
PP/EVAm10 & 156,4 & 63,1 \\
\hline
\end{tabular}

Fonte: Autoria própria.

\subsubsection{Ensaios mecânicos das blendas de iPP por tração}

Os ensaios mecânicos foram executados com o intuito de investigar o efeito dos copolímeros EVA65, EVAOH e EVAm nas propriedades mecânicas do iPP. As curvas tensão vs deformação do iPP e das suas respectivas blendas estão representadas na Figuras 26, assim como os resultados resistência à tração, módulo de elasticidade e elongação, dispostos na Tabela 17. 
Tabela 17 - Valores de resistência à tração, módulo de elasticidade e elongação do iPP e suas respectivas blendas

\begin{tabular}{lccc}
\hline Amostras & $\begin{array}{c}\text { Resistência à tração } \\
(\mathrm{MPa})\end{array}$ & $\begin{array}{c}\text { Módulo de elasticidade } \\
(\mathrm{MPa})\end{array}$ & $\begin{array}{c}\text { Elongação } \\
(\%)\end{array}$ \\
\hline iPP & $18,57 \pm 0,83$ & $1.049 \pm 22,8$ & $583,83 \pm 38,97$ \\
PP/EVA5 & $16,77 \pm 0,75$ & $1,039 \pm 17,0$ & $182,33 \pm 16,26$ \\
PP/EVA10 & $17,96 \pm 1,2$ & $1.033 \pm 34,8$ & $249,43 \pm 27,51$ \\
PP/EVAOH5 & $21,74 \pm 0,29$ & $1.163 \pm 28,2$ & $10,01 \pm 0,91$ \\
PP/EVAOH10 & $23,23 \pm 1,54$ & $1.241 \pm 58,4$ & $8,77 \pm 1,32$ \\
PP/EVAm5 & - & - & - \\
PP/EVAm10 & - & - & - \\
\hline
\end{tabular}

Fonte: Autoria própria.

Figura 26 - Curvas tensão vs deformação do iPP e de todas as blendas.

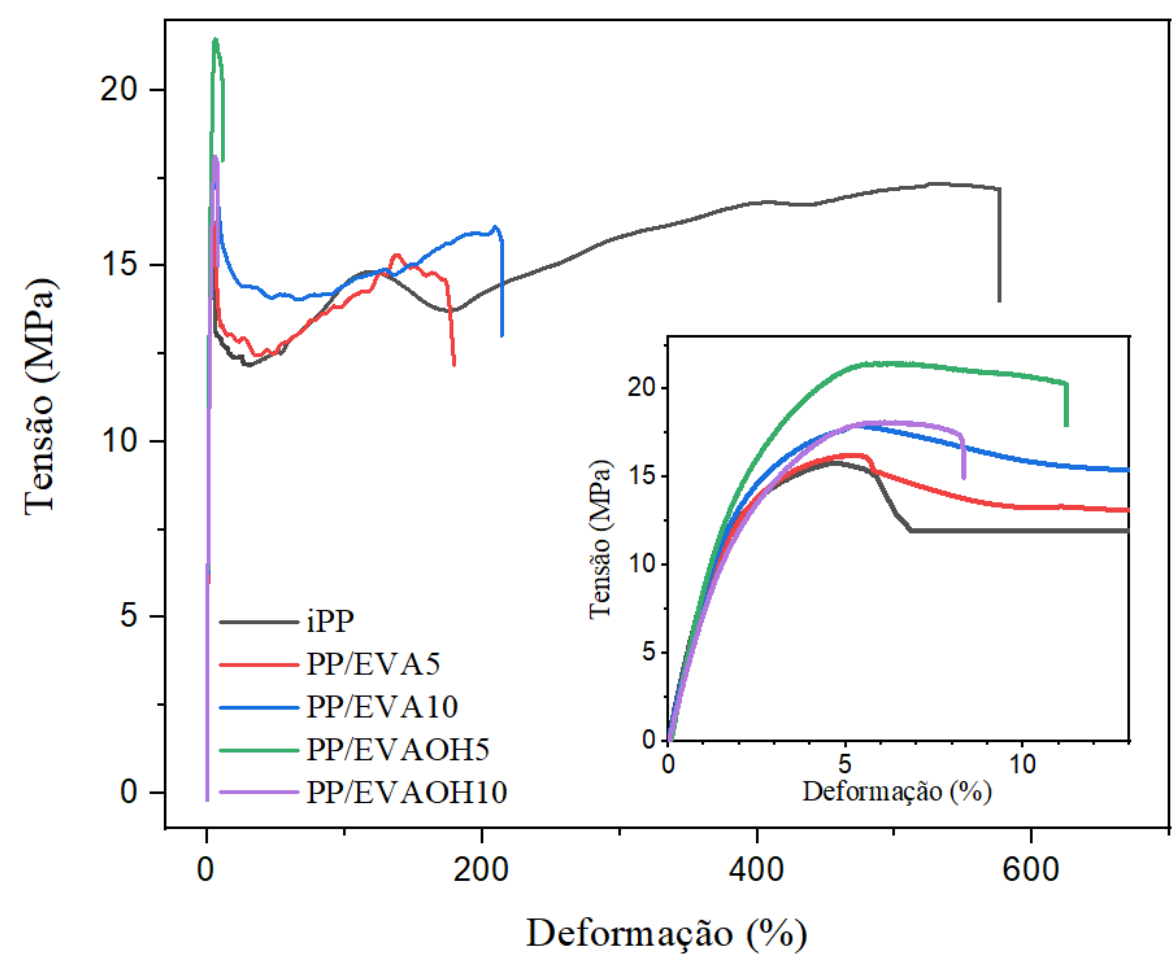

Fonte: Autoria própria.

Os corpos de prova das blendas PP/EVAm5 e PP/EVAm10 apresentaram pequenas fraturas no momento em que foram estampados. Dessa forma, os dados obtidos no ensaio não foram reportados. Essa fragilidade observada pode ter ocorrido porque o EVAm foi particulado em um moinho criogênico, utilizando-se $\mathrm{N}_{2}$ líquido, juntamente com o iPP. Mesmo assim, o tamanho de partícula alcançado apresentava o diâmetro entre 0,5 e 1,0 mm. Após o preparo por dissolução, o qual o EVAm se manteve insolúvel, a blenda foi prensada a 
$190{ }^{\circ} \mathrm{C}$. Nessa temperatura o iPP flui, enquanto o EVAm se mantém estável e, após o resfriamento, são observados defeitos na interface desses materiais.

Em nenhuma das blendas foi observado ganho na elongação na ruptura. Blendas iPP/EVA alcançam maiores valores de elongação apenas para EVAs de baixo teor de VA, enquanto que para maiores valores de VA, foram relatados aumentos na resistência à tração e ao impacto. Porém, nas blendas iPP/EVA65 houve redução tanto no módulo elástico quanto na resistência à tração. Esta observação corrobora com o fato de que a técnica de mistura por dissolução pode não ter sido eficiente para todas as blendas. ${ }^{41,42}$

Para blendas iPP/EVAOH foi observado o aumento da rigidez no material em comparação ao iPP puro. As blendas apresentaram menor elongação e maiores valores de resistência à tração e módulo de elasticidade. Esse ganho foi relatado na literatura e se deve ao fato de que os grupos hidroxila dos meros álcoois vinílicos interagem entre si através de ligações de hidrogênios. Esse tipo de interação facilita a cristalização do material, assim como observado na Tabela 17, e justifica sua maior rigidez em relação ao iPP. 57,88 


\section{CONCLUSÕES}

Para as reações com o óleo de babaçu, rendimentos quantitativos foram comprovados por $\mathrm{RMN}-{ }^{1} \mathrm{H}$ para a redução dos triglicerídeos de babaçu, assim como para a hidrólise dos ésteres metílicos. Na reação de hidrólise do copolímero EVA65, o teor de grupos acetato de vinila convertidos para grupos hidroxila foi de $83,7 \%$. Tal rendimento foi medido pela retrotitulação do EVAOH na presença de piridina e anidrido acético.

As reações com o EVA65 foram acompanhadas por espectroscopia FTIR e TGA. Tanto a espectroscopia FTIR quanto a termogravimetria, demonstraram que houve sucesso nas reações de hidrólise do EVA65 e de esterificação do EVAOH, com a formação de um novo éster, o EVAm. Ambas as técnicas confirmaram o desaparecimento dos sinais do grupo acetato de vinila do EVA65 e o aparecimento dos sinais referentes aos grupos hidroxila no EVAOH, assim como na recuperação (em comparação ao EVA65) do perfil éster do EVAm com cadeias saturadas esterificadas.

O EVAm foi insolúvel em todos os solventes testados. Esta propriedade gerou obstáculos, como a impossibilidade de caracterização por $\mathrm{RMN}-{ }^{1} \mathrm{H}$ em solução, assim como foi realizado para as reações com o óleo de babaçu. A insolubilidade do EVAm pode ser explicada pela hipótese do surgimento de ligações cruzadas através das insaturações das cadeias graxas, visto que o óleo usado possui $13 \%$ de ácidos graxos insaturados, que podem reagir com outras funções orgânicas de forma a criar ligações entre segmentos de cadeia dos polímeros, gerando uma rede polimérica tridimensional insolúvel.

Nos ensaios de tração foi observado aumento na resistência à tração e no módulo de elasticidade para as blendas PP/EVAOH. Valores menores no elongamento foram identificados em todas as blendas em comparação ao iPP puro. Tal fato pode ser atribuído ao alto teor de acetato de vinila para as blendas de iPP/EVA65 e, para as blendas iPP/EVAOH e iPP/EVAm, pode ser atribuído ao método de mistura dos polímeros.

Uma forma possível de se contornar a hipótese de uma mistura ineficiente, é investigar detalhadamente as variáveis envolvidas nas reações da síntese do EVAm, a fim de se obter melhores rendimentos e reprodutibilidade, para que seja possível sintetizar quantidades razoáveis para a mistura mecânicas entre os polímeros. 


\section{REFERÊNCIAS}

1. Moore, E. P. Polypropylene handbook. (Hanser Publisers, 1996).

2. Fred, W. \& Billmeyer, J. Text book of polymer science. (John Wiley and Sons, 1984).

3. Li, Y., Li, Y., Han, C., Yu, Y. \& Xiao, L. Morphology and properties in the binary blends of polypropylene and propylene-ethylene random copolymers. Polym. Bull. 2851-2866 (2018) doi:10.1007/s00289-018-2533-5.

4. Pascual, J., Peris, F., Boronat, T., Fenollar, O. \& Balart, R. Study of the effects of multi-walled carbon nanotubes ao mechanical performance and thermal stability of polypropilene. Polym. Eng. Sci. 52, 733-740 (2012).

5. Paszkiewicz, S. et al. Characterization of polypropylene/poly(2,6-dimethyl-1,4phenylene oxide) blends with improved thermal stability. Polym. Bull. 75, 3679-3691 (2018).

6. Parija, S. \& A., B. Multiwalled carbon nanotubes-based polypropylene composites: Influence of interfacial interaction on the crystallization behavior of polypropylene. Polym. Eng. Sci. 57, 183-196 (2017).

7. Pessan, C., Larocca, N., Jr, E. \& Pessan, L. Caracterização de blendas PP/EVA/PP-GMA através de reometria de torque e análises mecânicas. CBPol 1-8 (2009).

8. Da Silva, C. X., Álvares, D. R. S. \& Lucas, E. F. New additives for the pour point reduction of petroleum middle distillates. Energy and Fuels 18, 599-604 (2004).

9. Mansur, C. R. E., Passos, L. B., Alvares, D. R. S. \& Lucas, E. F. Modificação química de copolímero de etileno-coacetato de vinila (EVA) para ser testado como aditivo para óleo lubrificante. 2o Congr. Bras. P\&D em Petróleo Gás 2, 2-6 (2003).

10. Handbook of Polypropylene and Polypropylene Composites, Revised and Expanded. Handbook of Polypropylene and Polypropylene Composites, Revised and Expanded (2003). doi:10.1201/9780203911808.

11. Polypropylene: the definitive user's guide and databook. Choice Rev. Online (1998) doi:10.5860/choice.36-1596. 
12. Polypropylene Market To Reach USD 155.57 Billion By 2026. globenewswire https://cutt.ly/4fLN8RQ (2019).

13. Shubhra, Q. T. H., Alam, A. K. M. M. \& Quaiyyum, M. A. Mechanical properties of polypropylene composites: A review. J. Thermoplast. Compos. Mater. 26, 362-391 (2013).

14. Hisham A. Maddah. Polypropylene as a Promising Plastic: A Review. Am. J. Polym. Sci. 6, 1-11 (2016).

15. Resconi, L., Cavallo, L., Fait, A. \& Piemontesi, F. Selectivity in propene polymerization with metallocene catalysts. Chem. Rev. 100, 1253-1345 (2000).

16. Marques, M. de F. V., C. Junior, P. A., Guimarães, M. J. C. \& Coutinho, F. M. B. Catalisadores metalocênicos: aspectos gerais e heterogeneização. Polímeros (1998) doi:10.1590/s0104-14281998000300005.

17. Canevarolo Jr., S. V. Ciência dos Polímeros - Um texto básico para tecnólogos e engenheiros. Ciência dos Polímeros um texto básico para tecnólogos e Eng. (2006).

18. Hagen, H., Boersma, J. \& Van Koten, G. Homogeneous vanadium-based catalysts for the Ziegler-Natta polymerization of $\alpha$-olefins. Chem. Soc. Rev. 31, 357-364 (2002).

19. Work, W. J., Horie, K., Hess, M. \& Stepto, R. F. T. Definition of terms related to polymer blends, composites, and multiphase polymeric materials (IUPAC Recommendations 2004). Pure Appl. Chem. 76, 1985-2007 (2007).

20. Saldívar-Guerra, E. \& Vivaldo-Lima, E. Handbook of Polymer Synthesis, Characterization, and Processing. Handbook of Polymer Synthesis, Characterization, and Processing (2013). doi:10.1002/9781118480793.

21. Barreto Luna, C. B. et al. Desenvolvimento de Blendas Poliméricas visando a Tenacificação dos Polímeros: Uma revisão. Semin. Ciências Exatas e Tecnológicas (2015) doi:10.5433/1679-0375.2015v36n1p67.

22. Dikobe, D. G. \& Luyt, A. S. Morphology and properties of polypropylene/ethylene vinyl acetate copolymer/wood powder blend composites. Express Polym. Lett. 3, 190199 (2009).

23. da Silva, D., Luna, C., Araújo, E. \& da Silva, A. BLENDAS POLIMÉRICAS: 
CONCEITOS, OBTENÇÃO E APLICAÇÕES. Rev. Eng. E Tecnol. (2016).

24. Khan, I., Muhammad, M. \& Mazumder, M. A. J. Polymer Blends. Introduction to Polymer Compounding: Raw materials (Vol 1) vol. 1 (2014).

25. Quental, A. C., De Carvalho, F. P., Dos Santos Tada, E. \& Felisberti, M. I. Blendas de PHB e seus copolímeros: Miscibilidade e compatibilidade. Quim. Nova 33, 438-446 (2010).

26. Flory, P. J. \& Krigbaum, W. R. Thermodynamics of High Polymer Solutions. Annu. Rev. Phys. Chem. (1951) doi:10.1146/annurev.pc.02.100151.002123.

27. Thomas, S., Grohens, Y. \& Jyotishkumar, P. Characterization of Polymer Blends: Miscibility, Morphology and Interfaces. Characterization of Polymer Blends: Miscibility, Morphology and Interfaces (2015). doi:10.1002/9783527645602.

28. Schneider, C., Langer, R., Loveday, D. \& Hair, D. Applications of ethylene vinyl acetate copolymers (EVA) in drug delivery systems. J. Control. Release 262, 284-295 (2017).

29. Almeida, A. et al. Ethylene vinyl acetate as matrix for oral sustained release dosage forms produced via hot-melt extrusion. Eur. J. Pharm. Biopharm. 77, 297-305 (2011).

30. Tambe, S. P., Singh, S. K., Patri, M. \& Kumar, D. Ethylene vinyl acetate and ethylene vinyl alcohol copolymer for thermal spray coating application. Prog. Org. Coatings 62, 382-386 (2008).

31. Hirata, Y., Marais, S., Quang, T. N., Cabot, C. \& Sauvage, J. P. Relationship between the gas and liquid water permeabilities and membrane structure in homogeneous and pseudo-bilayer membranes based on partially hydrolyzed poly(ethylene-co-vinyl acetate). J. Memb. Sci. 256, 7-17 (2005).

32. De Moraes, E. A. Estudo da influência do teor de acetato de vinila na morfologia e biodegradabilidade de blendas poli(ácido lático)/polietileno-co-acetato de vinila. (Universidade de São Paulo, 2017).

33. Choi, S. S. \& Chung, Y. Y. Simple analytical method for determination of microstructures of poly(ethylene-co-vinyl acetate) using the melting points. Polym. Test. 90, (2020). 
34. Pasanovic-Zujo, V., Gupta, R. K. \& Bhattacharya, S. N. Effect of vinyl acetate content and silicate loading on EVA nanocomposites under shear and extensional flow. Rheol. Acta 43, 99-108 (2004).

35. Zhang, W., Chen, D., Zhao, Q. \& Fang, Y. Effects of different kinds of clay and different vinyl acetate content on the morphology and properties of EVA/clay nanocomposites. Polymer (Guildf). 44, 7953-7961 (2003).

36. Alexandre, M. et al. Preparation and properties of layered silicate nanocomposites based on ethylene vinyl acetate copolymers. Macromol. Rapid Commun. 22, 643-646 (2001).

37. Wang, L., Fang, P., Ye, C. \& Feng, J. Solid-State NMR Characterizations on Phase Structures and Molecular Dynamics of Poly(ethylene-co-vinyl acetate). J. Polym. Sci. Part B Polym. Phys. 44, 2864-2879 (2006).

38. Arsac, A., Carrot, C. \& Guillet, J. Determination of primary relaxation temperatures and melting points of ethylene vinyl acetate copolymers. J. Therm. Anal. Calorim. 61 , $681-685$ (2000).

39. Brogly, M., Nardin, M. \& Schultz, J. Effect of vinylacetate content on crystallinity and second-order transitions in ethylene-vinylacetate copolymers. J. Appl. Polym. Sci. 64, 1903-1912 (1997).

40. Da Róz, A. L., Ferreira, A. M., Yamaji, F. M. \& Carvalho, A. J. F. Compatible blends of thermoplastic starch and hydrolyzed ethylene-vinyl acetate copolymers. Carbohydr. Polym. 90, 34-40 (2012).

41. Gupta, A. K., Ratnam, B. K. \& Srinivasan, K. R. Impact toughening of polypropylene by ethylene vinyl acetate copolymer. J. Appl. Polym. Sci. 45, 1303-1312 (1992).

42. Jafari, S. H. \& Gupta, A. K. Impact strength and dynamic mechanical properties correlation in elastomer-modified polypropylene. J. Appl. Polym. Sci. 78, 962-971 (2000).

43. Kakkar, D. \& Maiti, S. N. Effect of flexibility of ethylene vinyl acetate and crystallization of polypropylene on the mechanical properties of i-PP/EVA blends. $J$. Appl. Polym. Sci. 123, 1905-1912 (2012). 
44. Maes, C. et al. Recent Updates on the Barrier Properties of Ethylene Vinyl Alcohol Copolymer (EVOH): A Review. Polym. Rev. 58, 209-246 (2018).

45. Deng, P., Liu, M., Zhang, W. \& Sun, J. Preparation and physical properties of enhanced radiation induced crosslinking of ethylene-vinyl alcohol copolymer (EVOH). Nucl. Instruments Methods Phys. Res. Sect. B Beam Interact. with Mater. Atoms 258, 357-361 (2007).

46. Mokwena, K. K. \& Tang, J. Ethylene Vinyl Alcohol: A Review of Barrier Properties for Packaging Shelf Stable Foods. Crit. Rev. Food Sci. Nutr. 52, 640-650 (2012).

47. Artzi, N., Narkis, M. \& Siegmann, A. Review of melt-processed nanocomposites based on EVOH/organoclay. J. Polym. Sci. Part B Polym. Phys. 43, 1931-1943 (2005).

48. de Lima, J. A. \& Felisberti, M. I. Porous polymer structures obtained via the TIPS process from EVOH/PMMA/DMF solutions. J. Memb. Sci. 344, 237-243 (2009).

49. Stenhouse, P. J., Ratto, J. A. \& Schneider, N. S. Structure and properties of starch/poly(ethylene-co-vinyl alcohol) blown films. J. Appl. Polym. Sci. 64, 2613-2622 (1997).

50. Kim, S. W. \& Cha, S. H. Thermal, mechanical, and gas barrier properties of ethylenevinyl alcohol copolymer-based nanocomposites for food packaging films: Effects of nanoclay loading. J. Appl. Polym. Sci. 131, 1-8 (2014).

51. Franco-Urquiza, E., Santana, O. O., Gámez-Pérez, J., Martínez, A. B. \& Maspoch, M. L. Influence of processing on the ethylene-vinyl alcohol (EVOH) properties: Application of the successive self-nucleation and annealing (SSA) technique. Express Polym. Lett. 4, 153-160 (2010).

52. Ezquerra, T. A., Šics, I., Nogales, A., Denchev, Z. \& Baltá-Calleja, F. J. Simultaneous crystalline-amorphous phase evolution during crystallization of polymer systems. Europhys. Lett. 59, 417-422 (2002).

53. Alvarez, V. A. \& Kenny, M. Isothermal Crystallization of Poly ( vinyl alcohol - co ethylene ). (2002).

54. Lagarón, J.-M. Multifunctional and nanoreinforced polymers for food packaging. Multifunct. Nanoreinforced Polym. Food Packag. 1-28 (2011). 
55. Lasagabaster, A., Abad, M. J., Barral, L. \& Ares, A. FTIR study on the nature of water sorbed in polypropylene (PP)/ethylene alcohol vinyl (EVOH) films. Eur. Polym. J. 42, 3121-3132 (2006).

56. Faisant, J. B., Aït-Kadi, A., Bousmina, M. \& Deschênes, L. Morphology, thermomechanical and barrier properties of polypropylene-ethylene vinyl alcohol blends. Polymer (Guildf). 39, 533-545 (1998).

57. Yeo, J. H. O., Lee, C. H., Park, C. \& Lee, K. Rheological, Morphological, Mechanical, and Barrier Properties of PP/EVOH Blends. 20, 191-201 (2001).

58. Sangeetha, V. H., Varghese, T. O. \& Nayak, S. K. Value Addition of Waste Cotton: Effect of Nanofibrillated Cellulose on EVA/EVOH Toughened Polylactic Acid System. Waste and Biomass Valorization 11, 4119-4128 (2020).

59. Verh, R. \& Stevens, C. V. Renewable bioresources: Scope and modification for nonfood applications. (2004).

60. Malacea, R. \& Dixneuf, P. H. Green metathesis chemistry: Great challenges in synthesis, catalysis and nanotechnology. (2010).

61. Zaliha, O., Chong, C. L., Cheow, C. S., Norizzah, A. R. \& Kellens, M. J. Crystallization properties of palm oil by dry fractionation. Food Chem. 86, 245-250 (2004).

62. Silva Ferreira, B., Pereira Faza, L. \& Le Hyaric, M. A comparison of the physicochemical properties and fatty acid composition of indaiá (Attalea dubia) and babassu (Orbignya phalerata) oils. Sci. World J. 2012, 1-4 (2012).

63. Magalhães, R. M. Obstáculos à exploração do baru (Dipteryx alata Vog.) no cerrado goiano: Sustentabilidade comprometida? (Universidade de Brasília, 2011).

64. Silva, M. R. da, Carvalho Júnior, O. A. de, Martins, É. de S., Mitja, D. \& Chaib Filho, H. Análise fatorial multivariada aplicada a caracterização de áreas de ocorrência de babaçu (Attalea speciosa Mart. ex Spreng) na bacia do Rio Cocal. Soc. Nat. 24, 267282 (2012).

65. Soler, M. P., Vitali, A. de A. \& Muto, E. F. Tecnologia de quebra do coco babaçu (Orbignya speciosa). Ciência e Tecnol. Aliment. 27, 717-722 (2008). 
66. Braskem. PP HP500N. https://cutt.ly/ef4Ehyr.

67. Santos, N. A. et al. Thermogravimetric and calorimetric evaluation of babassu biodiesel obtained by the methanol route. J. Therm. Anal. Calorim. 87, 649-652 (2007).

68. Fukuda, H., Kondo, A. \& Noda, H. Biodiesel fuel production by transesterification of oils. J. Biosci. Bioeng. 92, 405-416 (2001).

69. Geris, R. et al. Biodiesel de soja - Reação de transesterificação para aulas práticas de química orgânica. Quim. Nov. 30, 1369-1373 (2007).

70. Castro, M. P. De. Desenvolvimento de materiais híbridos oriundos de óleos vegetais, olefinas cíclicas e centros de rutênio. (Universidade de São Paulo, 2012).

71. Schuchardt, U., Sercheli, R. \& Matheus, R. Transesterification of vegetable oils: a review general aspects of transesterification. J. Braz. Chem. Soc., 9, 199-210 (1998).

72. Ferrari et al. Biodiesel de soja - Taxa de conversão em ésteres etílicos, caracterização físico- química e consumo em gerador de energia. Quim. Nov. 28, 19-23 (2005).

73. Rinaldi, R., Garcia, C., Marciniuk, L. L., Vitorino, A. \& Schuchardt, U. Síntese de biodiesel: uma síntese de biodiesel: Uma proposta contextualizada de experimento para laboratório de química. Quim. Nova 30, 1374-1380 (2007).

74. Isenmann, A. F. Princípios da síntese orgânica. (2018).

75. Oliveira, G. E., Mansur, C. R. E., Lucas, E. F., González, G. \& de Souza, W. F. The effect of asphaltenes, naphthenic acids, and polymeric inhibitors on the pour point of paraffins solutions. J. Dispers. Sci. Technol. 28, 349-356 (2007).

76. Amaral, D. N. Do. Cloreto de tionila (CAS No 7719-09-7). Rev. Virtual Química 5, 1204-1208 (2014).

77. Barison, A. et al. A simplemethodology for the determination of fatty acid composition in edible oils through 1H NMR spectroscopy. Magn. Reson. Chem. 48, 642-650 (2010).

78. Fernandes, H., Souza Filho, R. M., Silva Sá, J. L. \& Lima-Neto, B. S. Bio-based plant oil polymers from ROMP of norbornene modified with triglyceride from crude red 
palm olein. $R S C A d v .6,75104-75110$ (2016).

79. Solomons, T. W. G., Fryhle, C. B. \& Snyder, S. A. Organic chemistry 2. (2009).

80. Yin, J., Zhang, J. \& Yao, Y. Melt grafting of poly(ethylene-vinyl acetate) copolymer with maleic anhydride. J. Appl. Polym. Sci. (2006) doi:10.1002/app.24320.

81. Silverstein, R. M., Webster, F. X. \& Kiemle, D. J. Spectrometric identification of organic compounds 7ed 2005 - Silverstein, Webster \& Kiemle.pdf. Microchemical Journal (2005) doi:10.1016/0026-265X(76)90069-2.

82. Menczel, J. D. \& Prime, R. B. Thermal Analysis of Polymers: Fundamentals and Applications. Thermal Analysis of Polymers: Fundamentals and Applications (2008). doi:10.1002/9780470423837.

83. Costache, M. C., Jiang, D. D. \& Wilkie, C. A. Thermal degradation of ethylene-vinyl acetate coplymer nanocomposites. Polymer (Guildf). (2005) doi:10.1016/j.polymer.2005.05.084.

84. Zanetti, M., Camino, G., Thomann, R. \& Mülhaupt, R. Synthesis and thermal behaviour of layered silicate-EVA nanocomposites. Polymer (Guildf). (2001) doi:10.1016/S0032-3861(00)00775-8.

85. Matsuda, N., Shirasaka, H., Takayama, K., Ishikawa, T. \& Takeda, K. Thermal degradation and flame retardancy of ethylene-vinyl alcohol copolymer blended with ammonium polyphosphate. Polym. Degrad. Stab. (2003) doi:10.1016/S01413910(02)00229-X.

86. Alvarez, V. A., Ruseckaite, R. A. \& Vázquez, A. Kinetic Analysis of Thermal Degradation in Poly(ethylene- vinyl alcohol) Copolymers. J. Appl. Polym. Sci. 90, 3157-3163 (2003).

87. Alves, A. C. L. Blendas de amido termoplástico e poli (álcool vinílico-co-etileno) São Carlos. (USP, 2018).

88. Diani, J. \& Gall, K. Morphological, Thermal, Rheological, and Mechanical Properties of PP/EVOH Blends Compatibilized With PP-g-IA Jung. Society (2006) doi:10.1002/pen. 